$w^{\frac{37}{3^{3}} \cdot 4^{4}}$ LA -7372

gr:

MASTER

A Critical Review of Analytical Techniques for Safeguarding the Thorium-Uranium Fuel Cycle

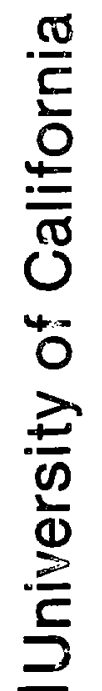

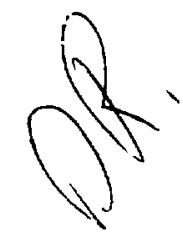




\title{
A Critical Review of Analytical \\ Techniques for Safeguaráing the \\ Thorium-Uranium Fuel Cycle
}

\author{
E. A. Hakkila
}

Issued: October 1978

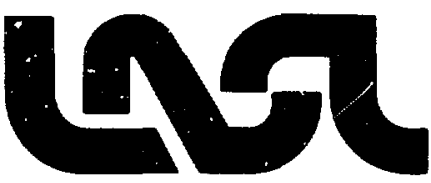




\title{
A CRITICAL REVIEW OF ANALYTICAL TECHNIQUES FOR SAFEGUARDING THE THORIUM-URANIUM FUEL CYCLE
}

\author{
by \\ E. A. Hakkila
}


Nuclear safeguards is becoming increasingly important in the public acceptance of nuclear energy. This holds true for the thorium-uranium fuel cycle as well as for the uranium-plutonium fuel cycle. Any materials measurement scheme must rely heavily on analytical chemistry both for primary accountability measurements and for calibration of NDA instruments.

The safeguards analytical chemistry needs in a plant designed to reprocess thcrium-uranium fuels require highly precise and accurate measurements of uranium as weil as plutonium. The $233_{U}$ (and ${ }^{235_{U}}$ for first-generation reactor fuel) must be measured with the same care given to plutonium. For fuels diluted with ${ }^{238} \mathrm{U}$, significant quantities of weapons-grade plutonium will be produced and must be measured accurately.

The approach to reprocessing thorium-uranium fuels will depend on fuel design and utilization philosophy. Fuel can be reprocessea in two separate recovery operations, a Purex plant for first-generation ${ }^{235} \mathrm{U}$ fuel and a Thorex plant for secondgeneration ${ }^{233} \mathrm{U}$ and blanket fuels, or a single plant can be used for all fuel types. In either case, accountability measurements will be required for uranium and plutonium product as well as feed and waste streams. This is in contrast to conventional LWR fuel reprocessing where stringent safeguards accountability is required only for the plutonium product stream.

In this report it is assumed that fuels were cooled 180 days before reprocessing. For short-cocled fuel another dimension in safeguards measurements would be the accountability of protactinium which would decay to high-purity ${ }^{23} \mathrm{U}$.

The sample selected for analysis must be representative of the bulk material being sampled. In Thorex or Purex reprocessing systems, several effects can alter the sample sufficiently to negate the most carefully conceived and administered analytical plans. In addition to the problems thorium-uranium samples share with plutonium, the high gamma fluxes associated with 
reprocessed thorium and ${ }^{233} \mathrm{U}$ product streams will require that all analytical manipulations be performed remotely in shielded facilities. Complex analytical operations performed with manipulators in shie:-ded caves could seriously affect measurement precision and accuracy.

Analytical problems associated with sample heat, radiolytic d.composition of reagents, polymerization, and radioactive sample decay must be considered in both the purex and Thorex systems. Many of these problems arise from the high radiation fields in the samples, particularly at the dissolver end of the streams where high beta-gamma fluxes are present and at the product end where high alpha-radiation levels characterize the concentrated product solutions. The situatior is further complicated by the high gamma-radiation levels resulting from decay daughters in the case of reprocessed ${ }^{233} \mathrm{U}$ and reprocessed thorium. Reagent stability must be considered in all analytical methods applied in righ radiation fields. Isotopic decay results in loss of plutonium in storage tanks and formation of impurities that may affect analytical results. Polymeric plutonium formed during reprocessing operations behaves erratically in analytical schemes. Problems in sampling and sample storage associated with high gamma fluxes will persist through the thorium and uranilun storage areas for Thorex reprocessing because of the radiation from decay products.

Isotope-dilution mass spectrometry will continue to be a key accountability measurement for hnth uranium and plitonium in dissolver solutions, not only because of its potential for high precision and accuracy but because isotopic analysos can be correlated with reactor data. Thorium also car be measured using a ${ }^{230}$ Th spike. Microsampling using a resin bead may permit independent off-site verification of isotopic composition. Electrometric mathods for uranium and plutonium measurement will be required for calibration rhecks of NDA instruments. Plutonium product also can be measured by electrometric titrations. In-line alpha monitors for plutonium and ir-line polarography for uranium may be developed for: waste-stream measurements but 
will be supplemented by spectrophotometric and fluorimetric methods for calibration checks.

Thorium, though not a fissile material, must be measured for accountability checks and to meet NRC and IAEA requiremerits. Gravimetry and EDrA tiŁrations probably will be the methods of choice. Thorium standard reference materials, certified by the National Bureau of Standards (NBS), are required for an effective accountability program and are being developed.

Automation of instrumentation for remote operation will be nectssary for many routine analyses because of the high radiation lovels associated with the Thorex uranium and thorium product streäms. Much work already has been done in this direction, including the autolnation of the spectrophotometric determination of uranium ard plutonium, potentiometric determination of uranium, controlled potentiometric determination of uranium and plutonium, mass-spectrometric determination of uranium and plutonium, and $x-r a y$ fluorescence analysis of all three elements. Remote-sampling techniques and small-sample methods will be important to minimize personnel exposure. In-line methods will be required not only for near-real-time accounting but also for minimizing exposure to personvel.

Most analytical methods for thorium and uranium have been developed and evaluated using the natural elements and for plutonium using weapons-grade matarial. Additional work is required to ensure that methods are applicable to reprocessed materials without significant loss of precision and accuracy under the radiation and remote operating constraints imposed by the thorium-uranium fuel cycle. 
CONTENTS

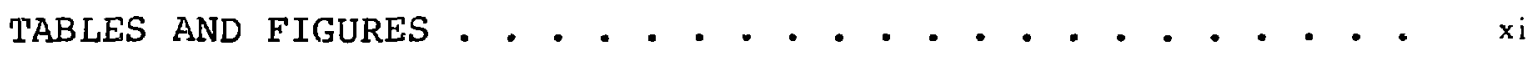

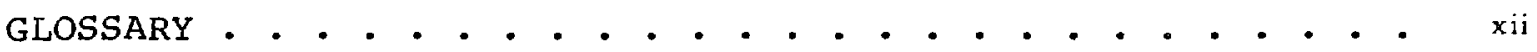

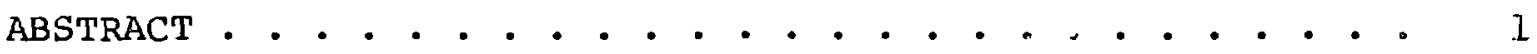

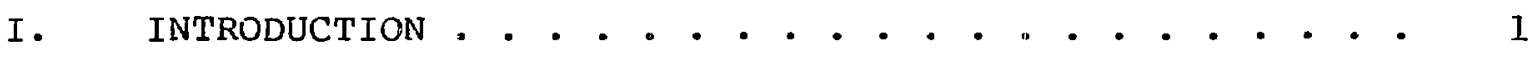

II. CHARACTERISTICS OF PROCESS STREAMS . . . . . . . . . . . 4

A. Characteristics of Product Streams . . . . . . . . 7

B. Characteristics of Waste Strecins . . . . . . . . . 8

1. Solid Wastes. . . . . . . . . . . . . . 8

a. Zircaloy Hulls... . . . . . . . . . 8

b. Centrifuge Sludge. . . . . . . . . . . 9

c. Second-Cycle $235_{U}$ Fuels. . . . . . . . . 10

2. High-Level Liquid Waste . . . . . . . . . 10

III. STANDARDS. • . . . . . . . . . . . . . . . . . . 10

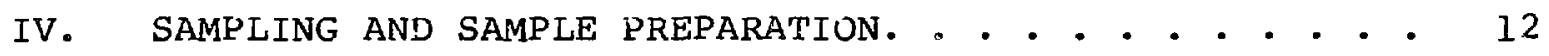

V. SEPARATION METHODS . . . . . . . . . . . . . . . . . 13

A. Precipitatiun. . . . . . . . . . . . . . 13

1. Thorium. . . . . . . . . . . . . . . 13

2. Uranium. . . . . . . . . . . . . . . 14

3. Plutonium. . . . . . . . . . . . . . 15

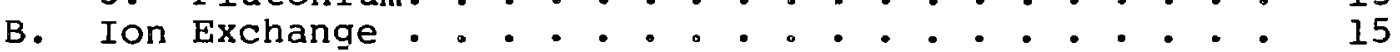

1. Thorium. . . . . . . . . . . . . . . 16

2. Uranium. . . . . . . . . . . . . . . . . I7

3. Elutonium. . . . . . . . . . . . . . 18

C. Solvent Extraction - . . . . . . . . . . . . . 18

l. Thoriumil. . . . . . . . . . . . . . . . . 22

2. Uranium. . . . . . . . . . . . . . . . . 23

3. Plutonium. • . . . . . . . . . . . . . 24

VI. CHEMICAL METHODS OF ANALYSIS • • • • • • • • • • • • • 24

A. Gravimetric Methods. . . . . . . . . . . . . 24

1. Thorium. . . . . . . . . . . . . . . 24

2. Urarium. • . . . . . . . . . . . . . . 26

3. Plutonium. . . . . . . . . . . . . . . 27

B. Spectrophotonetric Methods . . . . . . . . . . 27

1. Thorium. . . . . . . . . . . . . . . . 28

2. Uranium. •. . . . . . . . . . . . . . 28

3. Plutonium. . . . . . . . . . . . . . 30 
c. Electrometric Titration Methods. . . . . . . 30

1. Thorium. . . . . . . . . . . . 32

2. Uranium. . . . . . . . . . . . . . 33

3. Plutonium. . . . . . . . . . . . . . 33

D. Polarographic Methods. . . . . . . . . . . 35

1. Thorium. . . . . . . . . . . . . . 39

2. Uranium. . . . . . . . . . . . . . 39

3. Plutonium. . . . . . . . . . . . . 39

E. Compiexometric Titration . . . . . . . . . . 40

1. Thorium. . . . . . . . . . . . . . 40

2. Uranium. . . . . . . . . . . . . . . 41

3. Plutonium. . . . . . . . . . . . . . . . 41

F. Mass-Spectrometric Methods:.:.:.:.: 42

G. Alpha-Spectrometrici Methods. . . . . . . . . 45

H. Fluorimetric Methods . . . . . . . . . . 47

I. Specific-Ion Electrodes. . . . . . . . . . . 48

1. Thorium. . . . . . . . . . . . . . 48 48

2. Uranium. . . . . . . . . . ....... 49

3. Plutonium. . . . . . . . . . . . . . . . 49

J. X-Ray Fluorescence Techniques. . . . . . . . . 49

1. Selection of a Line. . . . . . . . . . . 50

2. Interferences. . . . . . . . . . . . 52

3. Applications to Reprocessing Samples... . 54

VII. PROBLEM AREAS. . . . . . . . . . . . . . . . 55

VIII, SUMMARY AND CONCLUSIONS. . . . . . . . . . . . 56

ACKNOWLEDGMENTS. . . . . . . . . . . . . . 58

REFERERCES • . . . . . . . . . . . . . . . 59 


\section{FIGURES}

1 Procuction and decay chains for ${ }^{232} \mathrm{U}$ (Ref. 1). . . 5

2 Precision of plutonium isotopic measurement. . . .

TABLES

I Isotopic Uranium and Plutonium Compositions of Thorium-Uranium Fuels. . . . . . . . . . . 6

II Percentages of Heavy Metals in Spent Fuel (Relative to Total Heavy Metals) . . . . . . . 7

III Composition of Feed Solutions for HTGR Fuel Reprocessing . . . . . . . . . . . . . 9

IV Precipitation Methods for Thorium Separation . . . 14

V Ion-Exchange Methods for Thorium Separation. . . • 17

VI Ion-Exchange Methods for Uranium Separation. • . . 19

VII Ion-Exchange Methods for Plutonium Separation. • • 20

VIII Solvent-Extraction Methods for Thorium Separation. • 23

IX Solvent-Extraction Metnods for Uranium Separation. . 25

X Solvent-Extraction Methods for Plutonium Separation. 25

XI Spectrophotometric Methods for Determination of Thorium, Uranium, and Plutonium. . . . . . . . 29

XII Electrometric Methods for Determining Uranium. . . 34

XIII Electrometric Methods for Plutonium Determination Using the Pu(VI)-Pu(IV) Couple... . . . . . 36

XIV Electrometric Methods for Plutonium Determination Using the Pu(III)-Pu(IV) Couple... . . . . . 37

XV X-Ray Lines Comonly Used for Uranium and Plutonium. 


$\begin{array}{ll}\text { CPC } & \text { Controlled potential coulometry } \\ \text { DME } & \text { Dropping-mercury electrode } \\ \text { DNNS } & \text { Dionyl-naphthalene sulfonic acid } \\ \text { DOE } & \text { Department of Energy } \\ \text { EDTA } & \text { (Ethylenedinitrilo)-tetraacetic acid } \\ \text { HTGR } & \text { High-temperature gas-cooled reactor } \\ \text { IAEA } & \text { International Atomic Energy Agency } \\ \text { LWBR } & \text { Light water breeder reactor } \\ \text { LWR } & \text { Light water reactor } \\ \text { MIBK } & \text { Methyl isobutyl ketone } \\ \text { NDA } & \text { Nondestructive assay } \\ \text { NBL } & \text { New Brunswick Laboratory } \\ \text { NBS } & \text { National Bureau of Standards } \\ \text { NRC } & \text { Nuclear Regulatory Commission } \\ \text { ORNL } & \text { Oak Ridge National Laboratory } \\ \text { PADAP } & \text { 2-(2-pyridylazo)-5-diethylaminophenol } \\ \text { PWR } & \text { Pressurized water reactor } \\ \text { SNM } & \text { Special nuclear material } \\ \text { SRM } & \text { Standard reference material } \\ \text { TBP } & \text { Tributyl phosphate } \\ \text { TOPO } & \text { Tri-n-octyl phosphine oxide } \\ \text { TTA } & \text { Thenoyltrifluoroacetone }\end{array}$


A CRITICAL REVIEW OF ANALYTICAL TECHNIQUES FOR SAFEGUARDING THE THORIUM-URANIUM FUEL CYCLE

by

E. A. Hakkila

\begin{abstract}
Conventional analytical methods applicable to the determination of thorium, uranium, and plutonium in feed, product, and waste streams from reprocessing thoriumbased nuclear reactor fuels are reviewed. Separations methods of interest for these analyses are discussed. Recommendations concerning the applicability of various techniques to reprocessing samples are included.
\end{abstract}

\title{
I. INTRODUCTION
}

Various analytical techniques have been developed for measuring thorium, uranium, and plutonium in ores, weapons-type materials, and/or reprocessing streams. With suitable precautions and modifications these methods are applicable to reprocessed materials from thorium-uranium fuels. The effectiveness of the techniques depends on factors such as sample type, sampling techniques, standards, and the skills of the chemists performing the work. Some of these factors will be discussed in detail.

Thorium-uranium fueled reactors convert fertile ${ }^{232}$ Th to ${ }^{233} \mathrm{U}$ while generating electricity by burning fissile fuel that can contain ${ }^{233} \mathrm{U},{ }^{235} \mathrm{U}$, or ${ }^{239} \mathrm{pu}$. Thus, both fissile and fertila fuels are required. Both may be present in the same fuel rods or the fertile material may be present as a thorium blanket surrounding a fissile uranium core. 
The fissile fuel consists of $\mathrm{UO}_{2}$ fuel elements similar to pressurized water reactor (PWR) fuel elements for conventional light water reactors (LWRS). Cladding may be Zircaloy or stainl sss steel. In the initial loading of the reactor core (referred to as the prebreeder), the fissile material is ${ }^{235} \mathrm{U}$ enriched up to $93 \%$. In addition to the $93 \%$ enrichment (high enriched), enrichments of 20-30\% (medium enriched) and <20\% (low enriched) are being considered. The thorium/uranium ratio is nominally between 5 and 10 , depending on reactor design. The fuel from the initial loading still contains significant amounts of $235 \mathrm{~J}$ at discharge, and recovery of the ${ }^{235} \mathrm{u}$ yalue is desirable. However, during burnup, significant amounts of ${ }^{236} \mathrm{U}$, a neutron poison, are produced; hence, it may be desirable to reprocess the uranium only once and to discard the second discharge without reprocessing. Subsequent refueling will be done with the ${ }^{233} \mathrm{U}$ recovered from the fertile $\mathrm{ThO}_{2}$ (referred to as the breeder or corverter). The ${ }^{23}{ }_{\mathrm{u}}$ may be mixed with $\mathrm{ThO}_{2}$ to form the breeder or converter fuel.

Also produced in the initial fissile loading is some plutonium Erom neutron absorption by ${ }^{238} \mathrm{U}$ as well as buildup from ${ }^{236} \mathrm{U}$. The U/Pu ratio will depend on the $235_{\mathrm{j}}$ enrichment of the fuel. The plutonium produced can be coprocessed with the recovered urarium and used to increase the fissile content of the fuel or it can be discarded to high-ievel liquid waste with the fission products.

The reprocessing of thorium-uranium fuels differs significantly from reprocessing in the uranium-plutonium cycle. The head end for oxide fuel elements is similar to that for LWR fuels, consisting of a chop-leach process. However, for $\mathrm{ThO}_{2}-\mathrm{UO}_{2}$ fuels, traces of $\mathrm{HF}$ are required to effect dissolution, and the presence of fluoride must be conside $\bar{d}$ in subsequent anaiytical schemes.

Two separate solvent-rxtraction systems are required to process the fissile and fertile fuels. A Thorex (thorium recovery by extraction) process for recovering ${ }^{233} \mathrm{U}$ in the fertile fuel 
is the more important from a safeguards viewpoint. A conventional Purex (plutonium-uranium xecovery by extraction) process for recovering uranium from fissile fuel can also recover plutonium but the characteristics of the uranium and plutonium are not necessarily similar to LWR fuel.

For the Thorex process the fertile particles are dissolved in a solvent $11-13 \underline{M}$ in $\mathrm{HNO}_{3}, 0.05 \mathrm{M}$ in $\mathrm{HF}$, and $0.1 \mathrm{M}$ in $\mathrm{Al}\left(\mathrm{NO}_{3}\right)_{3}$ (Thorex solution). Alternatively, zirconium from the Zircaloy cladding could serve as the fluoride complexant. The solution is centrifuged to remove solids which presumably consist primarily of Zircaloy fines and metallic fission-product ingots. The metallic ingots cuuld contain scme ${ }^{233} \mathrm{U}$.

The clarified solution containing uranium, thoriuri, and fission products is heated and steam-stripped to adjust the solution to an acid-deficient condition and to remove most of the $\mathrm{HNO}_{3}$ and $\mathrm{HF}$, and the $\mathrm{HNO}_{3}$ is adjusted to lM. The liranium and thorium are purified by a three-cycle solvent-exicraction system. In the first cycle--the high-acid extraction-uranium and thorium are removed from most of the fission products into a solution of $30 \%$ tributyl phosphate (TBP) in n-dodecane. The feed to the first cycle contains 200-250 g/L of thorium and 5-15 g/L of uranium. The uranium and thorium (and any plutonium and neptunium) are stripped into $0.1 \mathrm{M} \mathrm{HNO}_{3}$ and concentrated to $2250 \mathrm{~g} / \mathrm{L}$ of thorium. In the second cycle--the low-acid extraction, the $\mathrm{HNO}_{3}$ is adjusted to $0.1 \mathrm{M}$ and uranium and thorium are again extracted into $30 \%$ TBP in n-dodecane for further purification from fission products. An acid-strip column then removes most of the thorium, after which the uranium is stripped in a third column into $0.01 \mathrm{M} \mathrm{HNO}_{3}$. This solution is concentrated to $\sim 10 \mathrm{~g} / \mathrm{L}$ of uranium, sulfamic acid is added, the $\mathrm{HNO}_{3}$ is adjusted to $3.6 \underline{\mathrm{M}}$, and uranium is extracted in $5 \%$ TBP in n-dodecane (the third extraction of uranium). The uranium is stripped into $0.01 \mathrm{M} \mathrm{HNO}_{3}$ and becomes the uranium prodict from the Thorex process. 
For prebreeder fuel the $\mathrm{UO}_{2}$ is dissolved in $\mathrm{HNO}_{3}$, and after centrifuge clarification the solution is treated by a conventional Purex process.

II. CHARACTERISTICS OF PROCESS STREAMS

Three primary product streams result from the reprocessing of thorium-uranium fuels:

(1) Unreacted thorium from the Thorex process,

(2) ${ }^{233} \mathrm{U}$ from the Thorex process, and

(3) ${ }^{235} \mathrm{U}$ from the Purex process.

For low-enriched fuels $\left(<20 \%{ }^{235} \mathrm{U}\right.$ or $\left.<128{ }^{233} \mathrm{U}\right)$ the uranium product streams may contain co-processed plutonium, or plutonium may be recovered separately. The uranium and plutonium isotopic compositions differ significantly from LWR fuel reprocessing products and vary with initial fuel characteristics. For high-enriched fuels $\left(90 \%{ }^{235} \mathrm{U}\right.$ or $\left.{ }^{233} \mathrm{U}\right)$ the plutonium produced will be primarily ${ }^{238} \mathrm{Pu}$. As the fuel is diluted with $238_{U}$, the total plutonium concentration, especially the ${ }^{239} \mathrm{Pu}$ and higher plutonium isotopes, will increase. Likewise, the ${ }^{233} \mathrm{U}$ concentration in fissile fuel will depend on the dilution and number of passes through the reactor. The isotopic compositions of fresh and equilibrium recycle fuels are shown in Table $I$; the actinide compositions are summarized in Table II.

During the irradiation some ${ }^{232} \mathrm{U}$ is formed from a series of reactions starting either from neutron absorption by $230 \mathrm{Th}$ or an $(n, 2 n)$ reaction in ${ }^{232} T h$. The $(n, 2 n)$ reaction threshold requires a neutron energy $>6.37 \mathrm{MeV}$, and for well-thermalized reactors ${ }^{230} \mathrm{Th}$ is the main source of $232 \mathrm{U}$. The source of ${ }^{230} \mathrm{Th}$ in thorium ores is the decay of ${ }^{238} \mathrm{U}$ and is therefore a function of ore type. Thorium ores obtained as a by-product of phosphate manufacturing typically have : a ${ }^{230} \mathrm{Th}$ concentration of $w 10 \mathrm{ppm}$, whereas ores from uranium-bearing regions may contain up to $100 \mathrm{ppm}{ }^{230} \mathrm{Th} .{ }^{4}$ The production and decay chains for ${ }^{232} \mathrm{U}$ are summarized in Fig. 1 . The ${ }^{232} \mathrm{U} i$; an alpha emitter with a half-life of 74 yr and poses no severe 


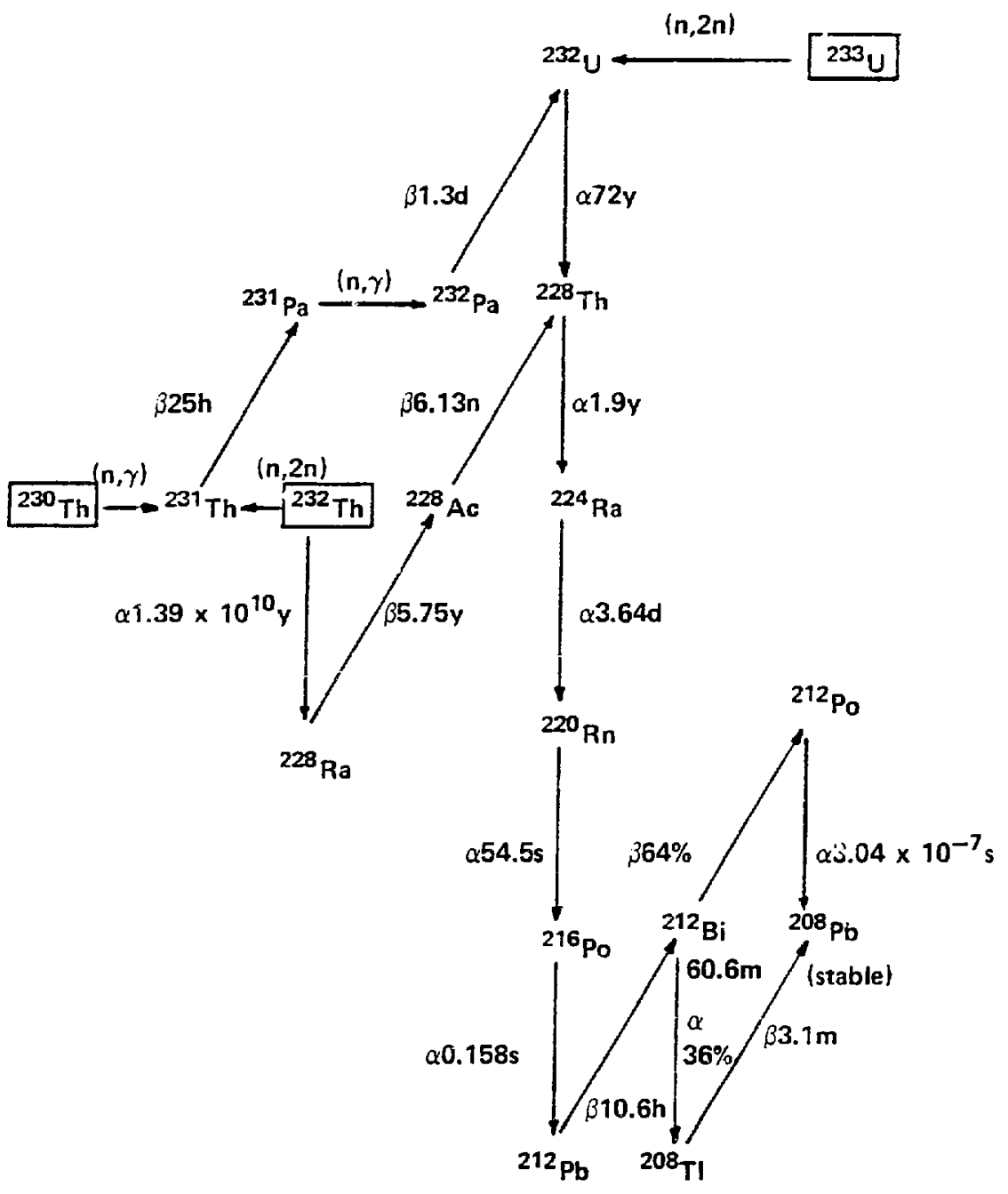

Fig. 1. Production and decay chains for ${ }^{232} \mathrm{U}$ (Ref. i). 


\section{TABLE I}

\section{ISOTOPIC URANIUM AND PLUT' NTUM COMPOSITIONS \\ OF THORIUM-URANIIJM FUELS}

\begin{tabular}{|c|c|c|c|}
\hline Isotope & $\begin{array}{l}\text { First Cycle, } \\
\text { Th Blanket } \\
(8) \\
\end{array}$ & $\begin{array}{c}\text { Enriched, } \\
\text { Equilibrium } \\
(q) \\
\end{array}$ & $\begin{array}{l}\text { Denatured, } \\
\text { Equilibrium } \\
(8)\end{array}$ \\
\hline $232_{U}$ & $0.01-0.1$ & 0.01 & 0.04 \\
\hline${ }^{233} \mathrm{U}$ & 92 & 18.5 & 7.3 \\
\hline${ }^{234} \mathrm{U}$ & 7.3 & 42.8 & 2.5 \\
\hline${ }^{23} 5_{U}$ & 0.6 & 24.7 & 1.0 \\
\hline${ }^{236} \mathrm{U}$ & 0.02 & 12.5 & 0.3 \\
\hline${ }^{238} \mathrm{U}$ & -- & 1.5 & 88.8 \\
\hline${ }^{238} \mathrm{Pu}$ & 75 & 83.4 & 0.8 \\
\hline${ }^{239} \mathrm{Pu}$ & 12 & 13.2 & 62.2 \\
\hline${ }^{240} \mathrm{Pu}$ & 6 & 2.5 & 23.7 \\
\hline $2^{24} 1_{\mathrm{Pu}}$ & 4 & 0.7 & 10.3 \\
\hline${ }^{242} \mathrm{Pu}$ & 3 & 0.1 & 3.0 \\
\hline
\end{tabular}

a $\operatorname{Ref} \cdot 1$.

b Ref. 2, $\mathrm{P}_{\dot{2}} \mathrm{~B}^{\mathrm{B}}-28$; steady state composite of mixture of fully enriched $235 \mathrm{U}$ and recycled uranium product.

C Ref. 2, p. B-44; product from $\mathrm{Th}-233 \mathrm{U}$ breeder.

problems, but all subsequent decay products are relatively short-lived and reach transient equilibrium rapidly. The ${ }^{208} \mathrm{Tl}$ daughter in the decay chain is an intense i?-min, 2.6-MeV) gamma emitter, and all manipulations of materials more than a few weeks old, including fuel fabrication and analytical chemistry, must be performed in shielded caves.

The thorium product stream from the Thorex process does not present a safeguards problem. Second-cycle ${ }^{235} \mathrm{U}$ fuel will be 
TABLE II

PERCENTAGES OF HEAVY METALS IN SPENT FUEL

(Relative to Total Heavy Metals)

Fuel Type

Th $235 \mathrm{U}$

Element

Thorium

Uranium

Plutoni um

Other actinides

Th Blanket

95

5

0.04

0.1
Enriched,

Equilibrium

91.5

8.4

0.026

0.1
Denatured, Equilibrium

73.3

26.3

0.3

0.01

\footnotetext{
a Calculated from data in Ref. 3.

b Ref. 2, p. B-28.

C Ref. 2, p. B-44.
}

discharged to high-level waste without processing and, because of the high radiation levels from the fission products, it too poses a minimal safeguards threat at present. However, accountability of the waste must be enforced because the waste might be reprocessed for plutonium content after a suitable cooling period of 50-100 yr.

The primary safeguards concerns will be the product streams containing $233_{\mathrm{U}},{ }^{235} \mathrm{U}$, and plutonium, with ${ }^{238} \mathrm{U}$ and thorium of secondary concern.

A. Characteristics of Product Streams

Two types of reactor cores will require reprocessing in a light water breeder reactor (LWBR) fuel cycle. These are the prebreeder and breeder cores. The prebreeder core consists of nodules of enriched uranium-dioxide $\left({ }^{235} \mathrm{UO}_{2}\right.$ in $\left.{ }^{238} \mathrm{UO}_{2}\right)$ rods and thoria $\left(\mathrm{ThO}_{2}\right)$ rods. The breeder-core concept consists of rods 
containing a binary mixture of ${ }^{233} \mathrm{UO}_{2}$ and $\mathrm{Tho}_{2}$, with the ${ }^{233} \mathrm{UO}_{2}$ concentration varying in different regions.

Chopped fuels containing $\mathrm{JO}_{2}$ or $(\mathrm{U}-\mathrm{Pu}) \mathrm{O}_{2}$ can be leached with $\mathrm{HNO}_{3}$ alone, but those containing $\mathrm{ThO}_{2}$ or $\left(\mathrm{Th}-{ }^{233} \mathrm{U}_{2} \mathrm{O}_{2}\right.$ will require an $\mathrm{HNO}_{3}$ leachant containing a trace of $\mathrm{HF}$ and perhaps some complexing agent to reduce $\mathrm{HF}$ astivity and concomitant corrosion.

The postdissolution separation requires two separate cycles: a Thorex cycle to separate uranium and thorium in the postbreeder feed and a Purex cycle to recover uranium from prebreeder fuel. The plutonium content of the fuel is lower than in LWR fuels, and plutonium can be recovered separately, coprocessed with the uranium, or discarded to high-level waste with the fission products.

The approximate makeups of process solutions to the Thorex and Purex processes are summarized in Table III. ${ }^{5}$ These data are representative of high-temperature gas-cooled reactor (HTGR) fuels, but similar compositions can be expected for LWR or LWBR fuels.

\section{B. Characteristics of Waste Streams}

The variability in product streams for reprocessing thorium-uranium fuels results in waste streams that are more complex than those from LWR fuel reprocessing. Considerably more solid wastes may be generated, primarily from the head end. Aaditives such as $\mathrm{Al}\left(\mathrm{NO}_{3}\right)_{3}$ will be required to complex $\mathrm{HF}$ from LWR cr LWBR fuels.

1. Solid Wastes. Solid wastes consist of

- Zircaloy hulls,

- Centrifuge sludge, and

- Second-cycle ${ }^{235} \mathrm{U}$ fuels.

a. Zircaloy Hulls. The Zircaloy hulls for IwR fuels are expected to contain 0.18 of the uranium fuel, ${ }^{6}$ and prebreeder fuel is expected to be similar. There has been no experience with the dissolving of Zircaloy-clad $\mathrm{ThO}_{2}-\mathrm{UO}_{2}$ fuels, but because they are more refractory, higher proportions of undissolved fuel may be encountered. 
COMPOSITION OF FEED SOLUTIONS FOR HTGR FUEL REPROCESSING

\begin{tabular}{|c|c|c|}
\hline Average liquid flow $(\bar{i} / \text { day })^{a}$ & 1479.6 & 1132.2 \\
\hline Heat load $(W / L)^{b}$ & 5.1 & 5.0 \\
\hline Activity $(\mathrm{Ci} / \mathrm{L})$ & 1351.9 & 1145.6 \\
\hline Carbon $(g / L)$ & 0.3 & 0.2 \\
\hline Uranium (g/L) & 7.3 & 0.0 \\
\hline Thor ium $(g / L)$ & 224.2 & Negligible \\
\hline Plutonium $(\mathrm{g} / \mathrm{L})$ & Negligible & 0.4 \\
\hline Fission products $(\mathrm{g} / \mathrm{L})$ & 7.3 & 15.5 \\
\hline Boron $(g / L)$ & -- & 0.4 \\
\hline $\mathrm{HNO}_{3}$ (ㅍ) & 8.4 & 2.0 \\
\hline$F^{-}(\underline{M})$ & 0.05 & -- \\
\hline $\mathrm{Al}^{+++}(\underline{\mathrm{M}})$ & 0.1 & -- \\
\hline $\mathrm{Cd}^{++}(\underline{M})$ & 0.075 & 0.075 \\
\hline Total $\mathrm{NO}_{3}^{-}$ & 13.0 & 2.5 \\
\hline
\end{tabular}

Thorex Leacher
Product

1479.6

Purex Leacher

Product

1132.2

5.0

1145.6

0.2

0.0

224.2

Negligible

Negligible

7.3

15.5

8.4

Boron $(g / L)$

0.05

0.1

0.075

0.075

13.0

a Exclusive of rework material.

$b$ Decay heat only.

b. Centrifuge sludge. The centrifuge sludge contains undissolved zircaloy fines and metallic ingots of noble-metal fission products. Studies on LWR oxide fuels have shown that some of the noble-metal ingots can contain as much as $25 \%$ uranium and 138 plutonium. ${ }^{7}$ The Zircaloy fines also may contain alloyed uranium and plutonium. In HTGR fuels, as much as 0.68 of the uranium may remain undissolved in the centrifuge solids. 8 
If that is also the case for LWBR fuels, either an accountabil-ity measurement must be made or an additional reprocessing step must be added to recover the uranium.

c. Second-cycle ${ }^{235}$ U Fuels. The fully enriched equilibrium fuel will contain appreciable amounts of the uranium as ${ }^{235} \mathrm{U}$. However, if. the fuel is not diluted with $233_{\mathrm{U}}$, the buildup of ${ }^{236} \mathrm{U}$ content may render it unusable for further recycling. For disposal, the fuel can be dissolved, and uranium and plutonium can be discharged to high-level waste with the fission products. Alternatively, the fuel can be stored as solids in high-level waste. The latter may have some advantage because a divertor would have to declad and dissolve the fuei before recovering the plutonium. In either case, accountability measurements are required.

2. High-Level Liquid waste. The high-level liquid waste consists of the aqueous wasce streams from the Thorex and Purex process streams and contains the bulk of the fission products, as well as an estimated $0.5 \%$ of the actinides. Some fluoride also will be present from the Thorex dissolution process.

\section{STANDARDS}

All procedures and instruments used for nuclear safeguards accounting should be calibrated against approved standara reference materialis. All weight and volume measurements should be traceable to National Bureau of Standards (NBS)-certified weight standards. NBS-certified Class $S$ weights are used as reference standards for laboratory measurements. Volume calibration is made by appropriate NBS-certified weights as reference standards. Analytical standards are defined by the subcomittee of the Analytical Chemistry Section of the International union of Pure and Applied Chemistry ${ }^{9}$ as follows:

Reference or atomic weight.

Ultimate standard: a substance that can be purified to virtuaily an atomic-weight standard. 
- Primary standard: a commercially available substance with a pusity of $100 \pm 0.02$ wtz.

Working standard: a substance of lower purity that car. be standardized against a primary standard.

The NBS distributes many materials for use as standards. These are referred to as "Standard Reference Materials" (SRMs) and may be a primary standard or one of lesser purity.

The primary standards available for use as oxidationreduction standards in the nuclear safeguards accountability program are:

- SRM 136C: potassium dichromate

- SRM 83c: arsenic trioxide

- SRM 40b: sodium oxalate.

SRMs available for uranium and plutonium analyses are shown in Ref. 10, p. 42. The uranium isotopic standards are well suited for the analysis of thorium-uranium fissile fuels. However, for fertile fuels secondary standards must be prepared because primary standards containing ${ }^{233} \mathrm{U}$ are not available. In addition to the NBS standards, standards for the spectrographic determination of impurities in uranium are obtainable from the New Brunswick Laboratory (NBL) and the Oak Ridge National Laboratory (ORNL). 11

Thorium primary standards presently are not available through the NBS, but reference macerials can be obtained from the NBL, and the NBS has initiated a program to develop a primary thorium standard.

Secondary or bench standards may be working standards obtained from a source such as NBS, from various Department of Energy (DOE) sontractors, or from international sources. 12 They also can be prepared from process solutions by characterization against NBS SRMS. The preparation and evaluation of secondary plutonium-nitrate standards have been described 13 and should be incorporated into the analytical laboratory standard operating procedure. The same techniques are applicable to preparation of uranium working standards irom plant uranium materials. These standards should be analyzed daily or by each 
shift to ensure that the method is under control. Process samples should not be analyzed until satisfactory values are obtained on bench standards.

\section{SAMPLING AND SAMPLE PREPARATION}

Measurements of process product ard waste streams will require the analysis of solids as well as solutions. Because of the high radiation levels associated with most process materials, remote sampling techniques will be required. The critical analytical points will be the accountability and product tanks for the Thorex and Purex processes. The waste streams will be of lesser importance but must be monitored, not only to measure the amounts of thorium, uranium, and plutonium going to waste, but to ensure that uranium and plutonium are not returned to process vessels for subsequent diversion.

The air-lift sampling system should be designed to permit extensive recirculation of solutions through the sample lines and the sample bottle. Vessel sparging, mixing time, and sample-circulation time should be considered in establishing proper sampling procedures for replicate samples. Any solids must be dissolved after sampling and be included in the total analysis. For highly radioactive samples the possibility of bubble formation must be considered in volume measurements, and temperature corrections should be applied.

The main sources of sampling error for solutions are expected to be (1) concentration or dilution of the sample by the air-lift system, (2) incomplete mixing of the solution in the tank, (3) contamination of the sample in the sample lines, and (4) sample heterogeneity caused by suspended solids. Where analytical precision better than $0.5 \%$ is required, all sampling should be done on a weight basis rather than a volume basis. Remote volume samplers seldom can provide routine precision better than $0.5 \%$, and even normal volumetric measurements are no better than 0.28 on a routine basis.

A sampling apparatus capable of providing pipetting accuracy of 0.18 under hot-cell conditions has been described. ${ }^{14}$ 
All steps, including pipet rinsing, are performed remotely, and the Teflon piston surface does not touch the solution being pipetted.

\section{SEPARATION METHODS}

Before chemical analysis the actinides often must be separated from each other or from other potentially interfering elements. For reprocessing solutions, the separation of fission products and other actinides, including protactinium, neptunium, and americium, must be considered. Unlike uranium and plutonium, thorium exists in solution only in the tetravalent state; hence, separations of thorium from other actinides rely on manipulating the valence of the uranium or plutonium. Fortunately, uranium commonly exists in solution as $\mathrm{UO}_{2}^{2+}$ and can be separated readily from thorium. Separation of thorium from plutonium generally is effected by oxidizing plutonium to $\mathrm{PuO}_{2}^{2+}$. Separations of plutonium from uranium rely on reducing plutonium to $\mathrm{Pu}^{3+}$ or $\mathrm{Pu}^{4+}$.

Some of the more common precipitation, ion-exchange, and solvent-extraction methods that might be useful for isolating thorium, uranium, and plutonium for safeguards applications will be discussed.

A. Precipitation

1. Thorium. The precipitation chemistry of thorium is reviewed in Ref. 15. The precipitating reagents commonly used for thorium are listed in Table IV. Many elements, including uranium and plutonium, interfere with the ammonium hydroxide and $\mathrm{H}_{2} \mathrm{O}_{2}$ precipitation but these techniques can be used for a rough separation of thorium from the rare earth fission products. Several reagents will effectively separate thorium from uranium, which is present as the $\mathrm{UO}_{2}^{2+}$ ion. However, most precipitation methods for thorium are also efficient methods for precipitation of plutonium as $\mathrm{Pu}^{3+}$ or $\mathrm{Pu}^{4+}$. Reducing reagents such as $\mathrm{H}_{2} \mathrm{O}_{2}$ and oxalic acid will reduce $\mathrm{PuO}_{2}^{2+}$ to $\mathrm{Pu}^{4+}$. The most common method for separating thorium from plutonium is fluoride precipitation following a perchloric-acid fuming to 


\section{PRECIPITATION METHODS FOR THORIUM SEPARATION}

Reagent

$\mathrm{NH}_{4} \mathrm{OH}$

$\mathrm{H}_{2} \mathrm{C}_{2} \mathrm{O}_{4}$

$\mathrm{H}_{2} \mathrm{O}_{2}$

$\mathrm{HF}$

$\mathrm{IO}_{3}$

Benzoic acid
Comments

Many interferences including $U$, Pu

Separates from U; Pu lanthanides interfere

U, Pu, lanthanides precipitate

Best for separating Th from Pu

Separates Th from lanthanides, U

Separate Th from lanthanides, U

oxidize plutonium to $\mathrm{PuO}_{2}^{2+}$. The precipitation must be carried out soon after the oxidation so that $\mathrm{PuO}_{2}^{2+}$ is not re-reduced to $\mathrm{Pu}^{4+}$, particularly in the presence of high beta-gamma radiation fields.

Some of the organic precipitants such as m-nitrobenzoic acid and p-aminosalicylic acid are of interest because they can be adapted to the titrimetric determination of thorium.15 Organic precipitants and precipitation conditions for thorium are listed in Ref. 15, p. 163. These can be applied more readily to hot cell measurements than can normal gravimetric methods.

2. Uranium. Precipitation methods for separating uranium are reviewed in Refs. 16 and 17. Precipitation is used infrequently to separate uranium in fuel reprocessing analysis, largely because of poor selectivity and the fact that ion exchange and solvent extraction are easier to apply under glovebox and hot-cell conditions. Ammonia can be used to precipitate uranium quantitatively, but thorium, plutonium, and lanthanide fission products are also precipitated. If $\mathrm{CO}_{2}$ has been absorbed from the atmosphere by the $\mathrm{NH}_{4} \mathrm{OH}$, some uranium can be lost by the formation of soluble carbonate complexes, hence, piridine or hexamethylenetetramine is more commonly used. 
The solubility of $\mathrm{UO}_{2}^{2+}$ carbonate complexes has been exploited to mask uranium in the separation of numerous ions from uranium by hydroxide precipitation.

3. Plutonium. The separation chemistry of plutonium is reviewed in Refs. 16, 18 and 19. Because of its multiple valences, plutonium affords more versatility in separation chemistry than does thorium or uranium. Tri- and totravalent plutonium are precipitated essentially quantitatively as the peroxides, oxalates, fluorides, and phosphates; tetravalent plutonium as the iodate; and all three common valences as the hydroxides. All of these reagents are useful in plutonium analytical chemistry. $\mathrm{PuF}_{4}$ is the most insoluble of the plutonium precipitates and is useful in separating plutonium from uranium. Phosphate precipitaition in which bismuth is used as a carrier will separate plutonium (and rare-earth fission products) from uranium. Plutonium can be separated from the rare earths by first oxidizing to $\mathrm{Pu}^{6+}$ with $\mathrm{Ce}^{4+}$-the earliest process used to recover plutonium from nuclear fuel.

For separating trace amounts of plutonium, coprecipitatior: techniques are used (Ref. 18, pp. 383-386). The main criterion for carrier selection is that the carrier must not interfere with the subsequent measurement of plutonium.

B. Ion Exchange

Cation and anion formation for the actinides is a complex function of many variables, including valence, acid type, and acid concentration. Ion-exchange methods for separating the actinides usually involve oxidation-reduction manipulations that enable selective adsorption on or elution from cation or anion exchangers. The ion-exchange chemistry of the actinides is reviewed in Ref. 20 .

The trivalent actinides show litile or no adsorption on anion exchangers at all acid concentrations in $\mathrm{HNO}_{3}$ and $\mathrm{HCl}$. The tetravalent actinides exhibit little or no anion adsorption at low $\mathrm{HCl}$ or $\mathrm{HNO}_{3}$ concentrations, but anion adsorption increases with jncreasing acidity. Arion formation is greater in $\mathrm{HNO}_{3}$ than in $\mathrm{HCl}$. Thorium is adsorbed on cation exchangers at 
$\mathrm{HNO}_{3}$ and $\mathrm{HCl}$ concentrations to 4 N. Reprocessing solutions generally contain $\mathrm{HNO}_{3}$, and analytical separations from this medium are of primary interest. Anion-exchange separations for actinides in $\mathrm{HNO}_{3}$ are reviewed in Ref. 21 .

Because of the similarities in chemical properties of the actinides and the fission-product lanthanides, media other than $\mathrm{HNO}_{3}$ will be required for effective analytical separations. The separation possibilities often can be expanded by diluting the $\mathrm{hiN}_{3}$ (or $\mathrm{HCl}$ ) with organic reagents. 22 Thus, thorium is not adsorbed onto anion exchangers from aqueous $\mathrm{HCl}$ at any concentration, but strong adsorption is observed from HCl solutions containing long-chain aliphatic alcohols such as butanol ${ }^{23}$ or other organic solvents such as acetone. ${ }^{24}$ use of reducing acids such as $\mathrm{HBr}$ or $\mathrm{HI}$ also can affect adsorption characteristics. ${ }^{25}$ For example, in HI solution plutonium should be reduced to $\mathrm{Pu}^{3+}$. Additional separation possibilities may be realized in neutral or carbonate solutions, particularly for uranium, which forms strong carbonate complexes. 26

For ion-exchange separations of highly radioactive samples such as dissolver solutions, inorganic exchangers may be preferable to the normal organic exchangers because of their higher resistance to radiation degradation. The various types of avaijable inorganic exchangers, and their applications, are reviewed in Refs. 27-29. Methods have been described for separating plutonium from uranium and fission products by using zirconium phosphate, ${ }^{30}$ and for separating uranium and plutonium from fission products using silica gel. 31

1. Thorium. Thorium is strongly adsorbed on cation exchangers from $\mathrm{HCl}$, $\mathrm{HNO}_{3}$, and $\mathrm{H}_{2} \mathrm{SO}_{4}$ below $\sim \underline{1}$. Thorium is not adsorbed on anion exchangers from $\mathrm{HCl}$ at any concentration, but is adsorbed from $20.1 \mathrm{~N} \mathrm{H}_{2} \mathrm{SO}_{4}$ and $>2 \mathrm{~N} \quad \mathrm{HNO}_{3}$. Although cation exchange can be used to separate thorium from uranium and plutonium, distribution coefficients are better on anion exchangers and these are preferred. Both $\mathrm{UO}_{2}^{2+}$ and $\mathrm{PuO}_{2}^{2+}$ are adsorbed on strong anion-exchange resins from $>6 \mathrm{~N}$ HCl. Thorium is not adsorbed and is effectively separated. 
Representative methods for separating thorium from uranium, plutonium, or fission products are summarized in Table $V$.

2. Uranium. Essenicially all ion-exch-inge work has been performea using the $\mathrm{U}^{\mathbf{*}}$ valence, and only hexavalent uranium is considered here. Uranyl ions can be adsorbed on cation exchangers from dilute $\mathrm{H}_{2} \mathrm{SO}_{4}(<0.5 \underline{\mathrm{N}})$. However, most analytical separations on cation exchangers are performed under conditions

\section{TABLE $V$}

ION-EXCHANGE METHODS FOR THORIUM SEPARATION

Exchanger

Exchanger

Dowex $\quad 50-x 8$

Dowex $50-\mathrm{x} 8$

Dower 50

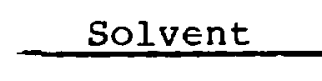

\section{Cation Method}

$0.6 \mathrm{~N} \mathrm{HCl}$ $90 \%$ alcohol

Uranyl chloride

$0.1 \mathrm{~N} \mathrm{HNO}_{3}$

Trace Th from $U$

$80 \%$ methanol-

2081 N $\mathrm{HNO}_{3}$
Ref. No.

\section{Anion Method}
Dowex $1-\mathrm{X} 4$
9. 6 N HCl
Uranyl nitrate
Dowex 1-x8
5-8 N HCl
R.E. fp's
36
Dowex 1-X8
558 ar:etone
R.E. $f P^{\prime} S$
108 6 N $\mathrm{HNO}_{3}$
Dowex 1-X8
6 N $\mathrm{HNO}_{3}$
R.E. fp's, U
Bio-Rad
$A G-I-X 8$
$0.7 \underline{\mathrm{N}} \mathrm{H}_{2} \mathrm{SO}_{4}$
U
Dowex 1-x8
908 acetone -
IN $\mathrm{HNO}_{3}$
$\overline{a_{\text {R.E. }}=\text { rare earth; }} f p=$ fission prodıct. 
conducive to anion formation for uranium, so that the impurity elements are adsorbed. Anion formation for the uranyl ion is enhanced by using complexing agents such as acetate, chloride, fluoride, nitrate, sulfate, or carbonate. Adsorption is strongest from diluie $(<0 . \underline{N}) \mathrm{H}_{2} \mathrm{SO}_{4}$ or strong $(6 \underline{\mathrm{N}}) \mathrm{HCl}$. Because thorium is not adsorbed from $\mathrm{HCl}$ at any concentration, separation of uranium from thorium is readily achieved. Tetravalent actinides are more strongly adsorbed on anion exchangers from 6N $\mathrm{HNO}_{3}$ than is uranium, and separations can be effected in that way.

Representative methods for separating uranium from thorium, plutonium, or fission products are summarized in Table VI.

3. Plutonium. Again, the multiplicity of valence states allows more versatility in separation schemes for plutonium than for thorium and uranium. Generally, adsorption proceeds in the order $\mathrm{Pu}^{4+}>\mathrm{Pu}^{6+}>\mathrm{Pu}^{3+}$ for anion exchangers, and $\mathrm{Pu}^{4+}>\mathrm{Pu}^{3+}$ $>\mathrm{Pu}^{6+}$ for cation exchangers (Ref. 18, pp. 277-279). Adsorption of $\mathrm{Pu}^{3+}$ and $\mathrm{Pu}^{4+}$ on cation exchangers is observed only at low concentrations $(<\mathrm{lN})$ of $\mathrm{H}_{2} \mathrm{SO}_{4}, \mathrm{HCl}$, and $\mathrm{HNO}_{3} \cdot$ Little, if any, adsorption on anion exchangers from $\mathrm{HCl}$ or $\mathrm{HNO}_{3}$ at any concentration is observed for trivalent plutonium. The $\mathrm{Pu}^{4+}$ and $\mathrm{Pu}^{6+}$ ions are strongly adsorbed from $>6 \underline{\mathrm{N}} \mathrm{HCl}$ and $>2 \underline{\mathrm{N}}$ $\mathrm{HNO}_{3}$. Separation of plutonium from thorium and uranium can be effected by reducing to $\mathrm{Pu}^{3+}$ with $\mathrm{HI}$ and adsorbing thorium and uranium on anion exchangers. Separation from the rare-earth fission products is effected by oxidizing to $\mathrm{Pu}^{6+}$ and adsorbing the rare earths as cations or adsorbing plutonium on anion exchangers.

Representative methods for separating plutonium from thorium, uranium, or fission products are summarized in Table VII. C. Solvent Extraction

Solvent extraction schemes exploit the solubility differences in the elements that are to be separated in two mutially immiscible solvents. Either the element to be analyzed is extracted into an organic phase, leaving the impurities in the aqueous phase, or the impurities are extracted into the organic 
TABLE VI

ION-EXCHANGE METHODS FOR URANIUM SEPARATION

Exchanger

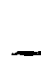

Solvent

Cation Method

\begin{tabular}{|c|c|}
\hline $\begin{array}{l}\text { Dowex } \\
\text { Ag }-50 w-x 8\end{array}$ & ${ }^{1} \mathrm{~N}: \mathrm{H}_{2} \mathrm{SO}_{4}$ \\
\hline Dowex 50-x8 & $\begin{array}{l}90 \% \text { tetra- } \\
\text { hydrofuran- } \\
10 \% 6 \mathrm{~N} \mathrm{HNO}_{3}\end{array}$ \\
\hline Dowex 50 & $1.5 \underline{\mathrm{N}} \mathrm{HNO}_{3}$ \\
\hline $\begin{array}{l}\text { Liquid cation } \\
\text { exchange }\end{array}$ & $0.5 \underline{\mathrm{NCl}}$ \\
\hline Silica gel & $\begin{array}{l}\text { Triethylene- } \\
\text { tetraamine- } \\
\text { hexaacetic acid } \\
\text { at } \mathrm{pH}=5-6\end{array}$ \\
\hline
\end{tabular}

Dowex 50

$$
\text { R.E. fp's, Th } \quad 40
$$

R.E. Ep's, Th, Mo, Zr 41

$\mathrm{Pu}^{3+} \quad 42$

R.E. Ep's, Th 43

Trace U from Th 44

Th

\section{Anion Method}

\begin{tabular}{|c|c|c|c|c|}
\hline Dowex & $1-\times 8$ & $\begin{array}{l}80 \% \text { met:hanol- } \\
208 \mathrm{gN} \mathrm{HCl}+ \\
\text { ascorbic acid }\end{array}$ & $\mathrm{Th}, \mathrm{Pu}$ & 45 \\
\hline Dowex & 1 & $\begin{array}{l}908 \text { ethanol- } \\
108 \mathrm{HNO}_{3}\end{array}$ & $\mathrm{Th}$ & 46 \\
\hline Dowex & $1-x 8$ & $\begin{array}{l}908 \text { methanol- } \\
108 \text { 6N } \mathrm{HCl}\end{array}$ & Th & 23 \\
\hline Dowex & 1 & $10 \mathrm{~N} \mathrm{HCl}$ & Th & 47 \\
\hline Dowex & $1-\times 8$ & $6 \underline{\mathrm{N}} \mathrm{HCl}$ & Th & 24 \\
\hline $\mathrm{De}-\mathrm{Aci}$ & idite FF & $10-11 \underline{N} \mathrm{HCl}+\mathrm{HI}$ & $\mathrm{Pu}$ & 48 \\
\hline Dowex & 1 & $12 \mathrm{~N} \mathrm{HCl}$ & R.E. $E p^{\prime} S_{*} T h$ & 49 \\
\hline Dowex & $1-x 8$ & $\begin{array}{l}80 \% \text { me thanol- } \\
20 \% 5 \mathrm{~N} \mathrm{HNO}_{3}\end{array}$ & $\mathrm{Th}_{1}$ & 50 \\
\hline Dowex & $1-\times 8$ & $\begin{array}{l}908 \text { dioxane- } \\
10 \% \text { 6N } \mathrm{HNO}_{3}\end{array}$ & $\mathrm{Tli}_{\mathrm{i}}$ & 51 \\
\hline Dowex & $1-x 8$ & $1 \mathrm{~N} \mathrm{HNO}_{3}$ & R.E. $\mathrm{fp}$ 's, Th & 52 \\
\hline
\end{tabular}

aR.E. = rare earth; $f p=f i s s i o n$ product. 
TABLE VII

ION-EXCHANGE METHODS FOR PLUTONIUM SEPARATION

Exchanger

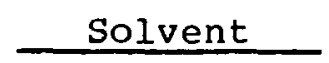

Application ${ }^{a}$

Ref. No.

\section{Cation Method}

$\mathrm{Zr}_{3}\left(\mathrm{PO}_{4}\right)_{4} \quad \begin{array}{ll}0.5 \mathrm{~N}^{2} \mathrm{HNO}_{3} \\ 0.02 \mathrm{~N} \mathrm{NaNO}_{2}\end{array}$

Silica gel

$4.5 \mathrm{~N} \mathrm{HNO}_{3}$

$\mathrm{U}, \mathrm{fp}$ 's

31,53

Dowex 50

$0.25 \mathrm{~N} \mathrm{HNO}_{3}$

$\mathrm{U}, \mathrm{fp}$ 's

54

$0.02 \overline{5} \mathrm{~N}$

hydroxylanine

\section{Anion Method}

Dowex 1

$9 \underline{\mathrm{N}} \mathrm{HCl}+\mathrm{SO}_{2}$

$U(V I), N P(I V)$

Dowex 1-x8

$7 \underline{\mathrm{N}} \mathrm{HNO}_{3}$

$\mathrm{U}, \mathrm{fp}$ 's

56

Dowex 1

$12 \underline{\mathrm{N}} \mathrm{HCl}$

Th

57

Dowex $1-x 2$

$7.2 \mathrm{~N} \mathrm{HNO}_{3}$

$U$ and many others

$\overline{a_{p}}=$ fission product.

phase. The distribution coefficient $\mathrm{K}_{\mathrm{d}}$ is the ratio of the relative concentrations of an element in the organic and the aqueous phases. A value of 1 for $\mathrm{K}_{d}$ indicates equal soluhility in the two phases; a value of $\mathrm{K}_{\mathrm{d}}>1$ indicates preferential solubility in the organic phase.

Extraction is effected by preferential solubility of an inorganic salt or associated complex of the element of interest in the organic solvent (ion-association extraction) or by addition of a chelating agent to the organic phase to form an extractable complex of the element of interest (chelate extraction). Extractability can be modified if the reaction equilibrium is driven in the desired direction by varying temperature, 
acid concentration, anion concentration, total ionic strength (salting-out), or by complex formation. As an example of the latter, fluoride will complex tri-or tetravalent p:utonium; carbonate in near-neuiral solutions will complex $\mathrm{UO}_{2}^{2+}$ and $\mathrm{PuO}_{2}^{2+}$, and (ethylenedinitrilo)-tetraaceticacid (EDTA) will complex many cations.

Actinide elements of the same valence often have similar extraction properties, and solvent-extraction separations of the actinides take advantage of the differenses in the extraction coefficients of different valence states. For separations of several actinides, more than one extraction may be required. For example, the tetravalent thorium and plutonium ions can be separated from hexavalent uranium by several methods, and thorium and plutonium can then be separated from each other either by reducing plutonium to $\mathrm{Pu}^{3+}$ or by oxidizing it to $\mathrm{PuO}_{2}^{2+}$.

Several solvent systems have been examined extensively as group extractants for the actinides and as solvents for individual actinides. Probably the most thoroughly studied system involves TBP in both $\mathrm{HNO}_{3}$ and $\mathrm{FiCl}$ solutions. Because of the high viscosity and density of pure TBP it must be diluted in some organic solvent, and aliphatic hydrocarbons such as kerosene are commonly used. The tetra- and hexavalent actinides are extracted by TBP. The extraction coefficients generally increase with increasing acid and ion concentrations because of salting-out effects. The tri-and pentavalent species show little solubility under any conditions.

Methyl-isobutyl ketone (MIBK or hexone) also is used as an extractant for nitrates of hexavalent actinides. Tetravalent species are extracted to a lesser extent, and tri- and pentavalent actinides remain almost quantitatively in the aqueous phase. Hexone can react explosively with strong $\mathrm{HNO}_{3}$ ' and extractions should be performed from <थ0.5N $\mathrm{HNO}_{3}$.

One of the more common chelate-extraction systems involves thenoyltrifluoroacetone (TTA) in solvents such as benzene or xylene. As a rule, only tho tetravalent species are extracted; hence, the system can be used to separate $\mathrm{Pu}^{4+}$ from $\mathrm{UO}_{2}^{2+}$, 
or $\mathrm{Th}^{4+}$ from $\mathrm{Pu}^{3+}$ or $\mathrm{vo}_{2}^{2+}$. The extraction coefficients for TTA are very sensitive to the presence of competing complexing agents, and best results are obtained from $\mathrm{HClO}_{4}$ solutions. Although $\mathrm{Pu}^{4+}$ can be extracted from $1.0 \mathrm{~N} \mathrm{HNO}_{3}$, it is nearly quantitatively back extracted in $6 \mathrm{~N} \mathrm{HNO}_{3} \cdot 59$

Other extraction systems have been studied for actinide separations, and some of the more appropriate extractants for analytical applications in thorium-uranium fuel reprocessing are summarized here. The method selected depends on the application. A coulometric or $x$-ray fluorescence measurement method may be tolerant of less-than-complete separation of plutonium from uranium but requires $100 \%$ recovery of the uranium. An isotope-dilution mass-spectrographic measurement requires complete removal of ${ }^{238} \mathrm{U}$ for quantitative measurement of ${ }^{238} \mathrm{Pu}$, but does not require $100 \%$ recovery of the plutonium.

1. Thorium. The most commonly used ion-association extraction for thorium involves extraction of the chlorides or nitrates irto a solution of TBP dissolved in an aliphatic hydrocarbon such as kerosene or n-dodecane. Extraction of thorium is most effective at high $\mathrm{HNO}_{3}$ and TBP concentrations, and distribution coefficients are further increased by replacing part of the $\mathrm{HNO}_{3}$ with nitrate salts. Extraction is hindered by fluoride, phosphate, and sulfate. Although uranium and plutonium also are extracted, separation from uranium is effected by manipulating acid concentration and from plutonium by manipulating plutonium valence. More efficient separation is achieved by extracting uranium from $\mathrm{HCl}$, leaving thoriun essentially quantitatively in the aqueous phase. 60,61

Mesityl oxide is another important extractant for thorium, particularly for separation from rare earths. ${ }^{6}$ Uranium extracts quantitatively. A disadvantage of mesityl oxide is the toxicity of its decomposition products. 63

Thorium separation schemes that may be applicable to Thorex and Purex reprocessing analyses are summarized in Table VIII. 
TABIE VIII

SOLVENT-EXTRACTILN METHODS FOR THORIUM SEPARATION

Agueous

$0.1 \mathrm{~N} \mathrm{ClO}_{4}, \mathrm{pH} 2$

$0.1 \underline{N} \mathrm{ClO}_{4}, \mathrm{pH} \quad 5-9$

$0.1 \mathrm{~N} \mathrm{HNO}_{3}$

6N $\mathrm{HCl}$

EDTA at $\mathrm{PH}=2.5$;

$\mathrm{HNO}_{3}$

\section{Organic ${ }^{a}$}

N-phenylbenzohydroxamic acid in chloroform

Oxine in hexone or chloroform

108 TTA in benzene

TOPO in xylene

TOPO in xylene
Application ${ }^{a}$

R.E.

R.E., U

R.E., U

66

R.E. fp's

U

68

${ }_{\text {R.E. }}$ = rare earth; $f p=$ fission product; $T$ TA = thenoyltrifluoroacetone .

2. Uranium. Extraction with TBP is widely used for separating uranium, extraction being improved at high acid, TBP, and salt concentrations. Although a number of elements, including thorium and plutonium, also are extracted, selection of proper extraction conditions can eliminate many interferences. For example, plutonium interference is eliminated by reduction to $\mathrm{Pu}^{3+}$ before extraction. Efficiency of separation from thorium is improved in $\mathrm{HCl}$ systems.

The hexone-HNO 3 system has been widely investigated for process application, and some analytical applications have been devised. 59 The method is useful for recovering uranium and plutonium from fission products, but because multiple extractions are necessary and separation of uranium and plutonium is difficult, the method probably has limited value in the analytical laboratory if quantitative recovery of uranium is required. It has been applied to HTGR reprocessing solutions for the subsequent isotope-dilution mass-spectrometric: measurement of 
uranium. 69,70 Extraction with tri-n-octylphosphine oxide (TOPO) also is used extensively, both from $\mathrm{HNO}_{3}$ and $\mathrm{HCl}$ media. ${ }^{71}$

Uranium extraction schemes that may be applicable to Thorex and Purex reprocessing analyses are sumarized in Table IX.

3. Plutonium. As mentioned, plutonium in the tetravalent or hexavalent states is extracted by most systems, such as TBP and hexone, that extract $\mathrm{Th}^{4+}$ or $\mathrm{UO}_{2}^{2+}$. In general, separacions of plutonium from thorium and uranium rely on control of the plutonium valence. Thenoyltrifluoroacetone in orgaric solvents such as xylene or benzene sonstitutes an important chelate-extraction system for tetravalent actinides. Separation of plutonium from uraniuiu is effected by performing the extraction from 1 N $\mathrm{HCl}$ while retaining uranium as $\mathrm{UO}_{2}^{2+}$. Plutonium can be separated from thorium by extracting $\mathrm{Th}^{4+}$ after reduction of plutonium to $\mathrm{Pu}^{3+}$. Similar schemes can be devised using other extraction systems such as TEP, hexone, or TOPO.

Plutonium extraction schemes that may be applicable to Thorex and Purex reprocessing analyses are summarized in Table $x$.

\section{CHEMICAL METHODS OF ANALYSIS}

A. Gravimetric Methods

Gravimetric methods involve separating a compound of the element to be determined and igniting it to a constant-weight stoichiometric compound. The method is appiicable only to relatively pure materials; impurities must be determined by spectrogrephic or other procedures and the final weight corrected by difference. When clean separations from impurities can be obtained, precisions better than $0.1 \%$ often can be realized.

1. Thorium. In general, reagents used for precipitation separations of thorium also can be used for gravimetric analysis. Whether precipitated as the hydroxide, peroxide, oxalate, or one of the numerous organic compouncis (Ref. 15, p. 183), the most 
TABLE IX

SOLVENT-EXTRACTION METHODS FOR URANIUM SEPARATION

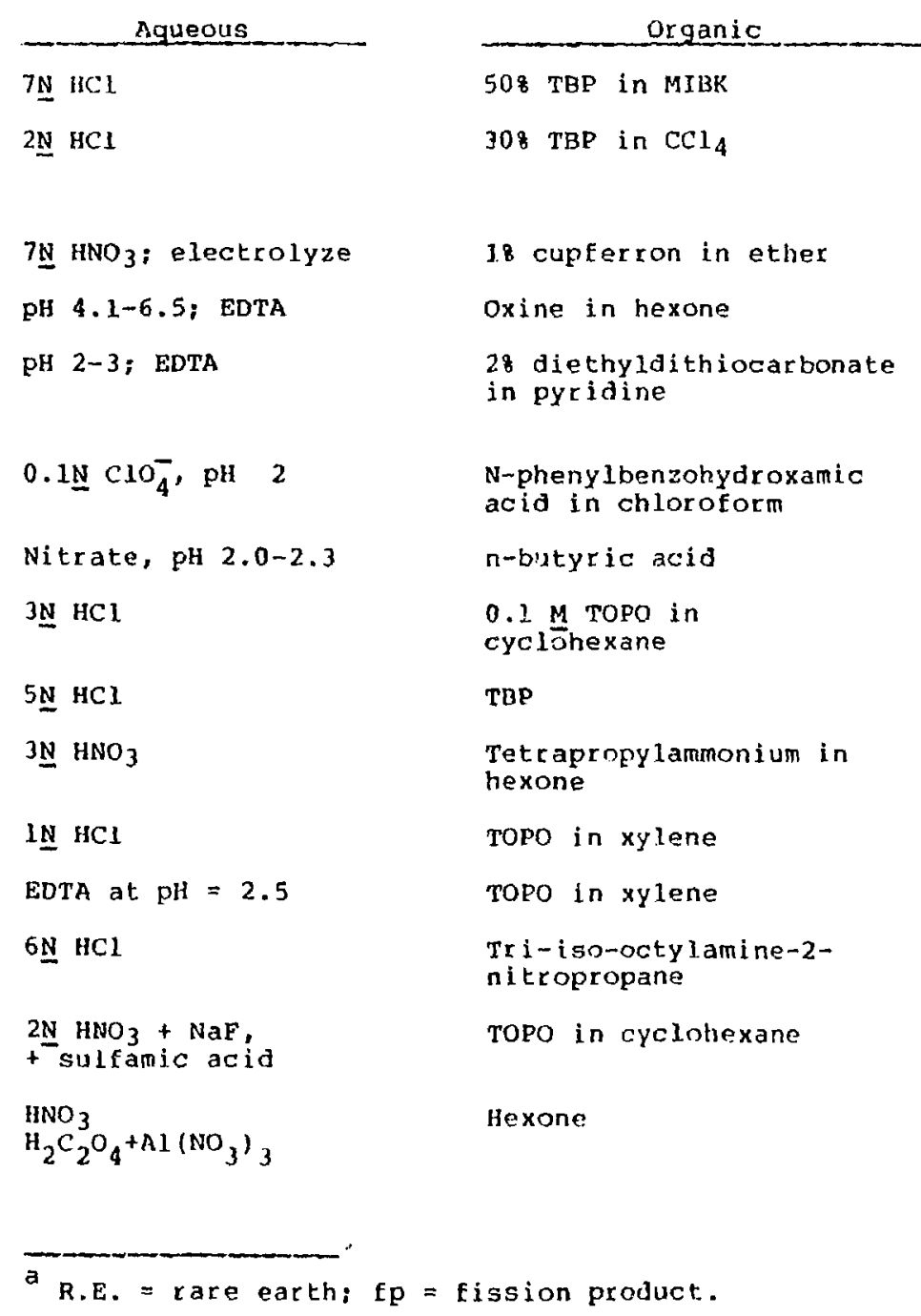

Application
Th
$U$ and pu from fp's
Eor $x-r a y$ floures-
cence analysis

R.E. fp's

Irradiated Th

Th

R.E., Th

กิ. $\mathrm{E}$, , 2 .

${ }_{\left(\mathrm{Pu}^{4}+\right)^{\mathrm{T}}}^{\mathrm{Th}}$

R.E. f.P's, Th

Ep's

R.F. FP's, Th

Th

From Th in UTGR

dissolver solution

Pu, others

Mass spectrometric determination of $y$ in HTGR dissolver solution
Ref. No.

60

70

72

73

64

74

75

76

77

67

63

78

79

R.E. $=$ rare earth; $\mathbf{f p}=$ fission product. 


\begin{tabular}{|c|c|c|c|}
\hline Agueous & Organic & Applications ${ }^{a}$ & Ref. No. \\
\hline $0.5-1.5 \underline{\mathrm{N}} \mathrm{HNO}_{3}$ & $0.5 \underline{N}$ TTA in xylene & R.E. Ep's, U, Th & 80 \\
\hline $3 \underline{N} \mathrm{HNO}_{3}$ & $\begin{array}{l}\text { Tet } r \text { apropy lammonium } \\
\text { in hexone }\end{array}$ & $\mathrm{Fp} \cdot \mathrm{s}$ & 81,82 \\
\hline $2 \underline{N} \mathrm{HCl}$ & 308 TBP in $\mathrm{CCl}_{4}$ & $\begin{array}{l}U \text { and Pu from fP's } \\
\text { products for } x-r \text { ay } \\
\text { flunrescence analysis }\end{array}$ & 60 \\
\hline $3 \underline{\mathrm{N}} \mathrm{HNO}_{3}$ & $\begin{array}{l}0.4 \mathrm{~N} \text { N-benzoylphenyl- } \\
\text { hydroxylamine (BPHA) in } \\
\text { chloroform }\end{array}$ & From $v$, fp's & 83 \\
\hline $6 \underline{\mathrm{N}} \mathrm{HNO}_{3}$ & $0.1 \underline{N}$ TOPO in cyclohexane & Lanthanide fp's & 84 \\
\hline $\begin{array}{l}11 \mathrm{~N} \mathrm{NH}_{4} \mathrm{NO}_{3} \\
+5 \mathrm{~N} \mathrm{HNO}_{3}\end{array}$ & Hexone & $v$ & 59 \\
\hline
\end{tabular}

common weighing form after ignition at a suitable temperature is $\mathrm{ThO}_{2}$.

Oxalate precipitation is used for the determination of thorium in nonradioactive leaching and aqueous solvent-extraction samples. 85 Precipitation is performed with $108 \mathrm{H}_{2} \mathrm{C}_{2} \mathrm{O}_{4}$ from $2 \mathrm{~N} \mathrm{HCl}$ and the precipitate is fired at $950^{\circ} \mathrm{C}$. Accuracy of 0.18 is claimed.

The method has been modified for determining thorium in the organic phase from TBP solvent extraction. 86

2. Uranium. Gravimetric methods can be used for the determination of uranium in pure product streams such as uranyl nitrate, $\mathrm{U}_{3} \mathrm{O}_{8}$ or $\mathrm{UO}_{2}$, and $\mathrm{UF}_{6}$. Nitrates are evaporated to $\mathrm{dry}-$ ness; $\mathrm{UF}_{6}$ is hydrolyzed in $\mathrm{H}_{2} \mathrm{O}$ and evaporated to dryness. Ignition is at $850-900 \mathrm{C}$ to $\mathrm{U}_{3} \mathrm{O}_{8}$ and the final weighing provides an RSD of 0.02 to $0.58 .87^{3}$ Ignition at temperatures $>946^{\circ} \mathrm{C}$ leads to formation of $\mathrm{UO}_{2}$; temperatures $<800^{\circ} \mathrm{C}$ yield slow decomposition reactions. ${ }^{88}$ Presence of $\mathrm{NO}_{3}^{-}, \mathrm{F}^{-}, \mathrm{Cl}^{-}$, or $\mathrm{SO}_{4}^{2-}$ dises not interfere, but the presence of $\mathrm{PO}_{4}^{3-}$ leads to formation of uranyl pyrophosphate rather than $\mathrm{U}_{3} \mathrm{O}_{8} \cdot 89$ 
3. Plutonium. Of the plutonium precipitates, only $\mathrm{PuO}_{2}$ is reported to form a compound suitable for gravimetric analysis (Ref. 18, pp. 297-298). Even with $\mathrm{PuO}_{2}$ the stoichiometry of the compound depends on initial composition and ignition temperatures, and even when heated to $1200^{\circ} \mathrm{C}$ the final composition is variable. In addition, $\mathrm{PuO}_{2}$ is hygroscopic, with the amount and rate of $\mathrm{H}_{2} \mathrm{O}$ adsorption dependent upon the ignition temperature. The suitability of gravimetry for determination of plutonium is dubious.

B. Spectrophotometric Methods

Spectrophotometric methods rely on the principle that a compound or complex in solution will absorb light of a specific wavelength in a quantity proportional to the concentration of the measured species. Generally, the concentration-absorbance function is a simple proportional relationship expressed by Beer's law, but variations may result at high concentrations or when other competing reactions occur. The RSD attainable by direct spectrophotometric methods usually is $0.5 \%$ or more and is seldom better than 0.28 . However, it can be improved to 0.058 with differential techniques that compare the absorbance of the unknown to a reference that is known precisely.

specificity in absorptiometry is a complex function of factors such as sharpness of absorption bands, specificity of reagents, other elements or compounds present, and the quality of the monocr omators. Specificity often can be improved by using preliminary separations, masking agents, and $\mathrm{pH}$ control. Because of the nonspecificity of reagents for thorium, uranium, and plutonium in the presence of each other and because of the nuclear reaction products (americium, neptunilm, fission products), time-consuming separations often are involved. These additional separations may limit the precision in major element analysis. For these reasons, spectrophotometric methods are of limited use for measuring uranium and plutonium in a fuel reprocessing plant, usually for process control and analysis of waste streams. 
The sensitioity of many spectrophotometric reagents to high radiation levels necessitates several supplenental separations during analysis of dissolver or waste-stream solution, even in the absence of elemental interference.

1. Thorium. A number of dye reagents form intensely colored complexes with thorium and have been investigated for the spectrophotometric determination of thorium. Unfortunately, most reagents that react with thorium also form colored comm pounds with the rare earths and with uranium, plutonium, and other actinides. Separations procedures or masking agents coupled with $\mathrm{pH}$ control often are required to eliminate interferences.

Probably the most important chromogenic reagent for thorium determination is thoron, the disodium salt of 2-(2-hydroxy-3, 6-disu: (o-1-naphthylazo)-benzene arsonic acid. The reagent is sensitive to a few micrograms of thorium but more than a few tenths of a milligram of rare earths or uranium will interfere. ${ }^{90}$ The method has been adapted to determination of thorium in both aqieous and organic phases from Thorex solvent extraction. ${ }^{91}$

Spectrophotometric methods of interest to measuring thorium in reprocessing samples are summarized in Table XI.

2. Uranium. Spectrophotometric methods for determining uranium in reprocessing streams generally are limited to measurement of trace concentrations of uranium in waste streams and possibly in the final product thorium and plutonium. Reagents of interest are listed in Table XI.

The method for determination of uranium with 2-(2pyridylazo)-5-diethylaminophenol (PADAP) has been modified specifically for determining uranium in reprocessing-plant waste streams 99 and in plutonium nitrate and oxide products. 100 The method for determination of uranium as the tetrapropylammonium complex has been modified to increase the tolerance for thorium in Thorex processing samples. ${ }^{107}$ The method also has been automated for determining uranium and plutonium simultaneously in scrap materials. 105 
TABLE XI

SPECTROPIOTOMETRIC METHODS FOR DETERMINATION OF TIORIUM, URANIUM, AND FLUTONIUM

\begin{tabular}{|c|c|c|c|c|c|}
\hline Element & Compound & $\begin{array}{l}\text { Concentration } \\
\text { Range or } \\
\text { Amount/Sample }\end{array}$ & $\begin{array}{r}\text { RSD } \\
(3) \\
\end{array}$ & Interferences; Comments ${ }^{a}$ & Ref. No. \\
\hline Th & Thoron & $25-750 \mu \mathrm{g}$ & 2 & $\mathrm{U}>5 \mathrm{mg}$ & 91 \\
\hline Th & $\begin{array}{l}\text { Solochromate } \\
\text { fast red }\end{array}$ & $i-200 \mu g$ & 1.5 & $\begin{array}{l}\text { R.E.'s, } \mathrm{Ee}, \mathrm{zr}, \mathrm{E}^{-}, \mathrm{PO}_{4}^{3-} \\
\text { others }\end{array}$ & 92 \\
\hline Th & SPADNS & $0.04-10 \mu \mathrm{g}$ & -- & $\mathrm{Zr}, \mathrm{PO}_{4}^{3-}, \mathrm{F}^{-}, \mathrm{SO}_{4}^{2-}, \mathrm{C}_{2} \mathrm{O}_{4}^{2-}$ & 93 \\
\hline Th & Arsenazo-III & $1-25 \mu \mathrm{g}$ & -- & $\mathrm{Pu}^{4+}, \mathrm{u}^{4+}$ & 94 \\
\hline $\mathbf{U}$ & Uranyl nitrate & $10-300 \mathrm{~g} / \mathrm{L}$ & $1-5$ & Temperature-sersitive & 95,96 \\
\hline $\mathbf{U}$ & Dibenzoy lnethane & $30-750 \mu \mathrm{g}$ & 1.7 & $\begin{array}{l}\mathrm{Ce}, \mathrm{Th}, \mathrm{W}, \operatorname{Fe}(\mathrm{III}), \mathrm{Cr}(\mathrm{IV}) \text {; } \\
\mathrm{Pu} \text { at } \mathrm{Pu} / \mathrm{U}>2\end{array}$ & 97 \\
\hline $\mathbf{u}$ & Peroxide & $1-25 \mathrm{mg}$ & & $\mathrm{Cr}, \mathrm{Cu}, \mathrm{Fe}, \mathrm{Mn}, \mathrm{Ni}$ & $88, b_{98}$ \\
\hline $\mathbf{U}$ & PADAP & $1-100 u g$ & 5 & 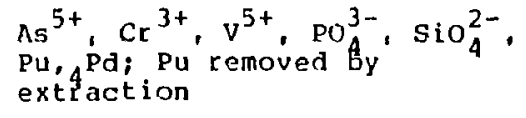 & 99,100 \\
\hline $\mathbf{u}$ & PAR & $1-100$ uy & $?$ & R.E.'s, Th(IV), Pu(IV)? & 101 \\
\hline $\mathbf{U}$ & $5-M e--$ PAN & $10-80 \mu \mathrm{Hg}$ & $?$ & $\begin{array}{l}\text { F-; extraction removes nost } \\
\text { interfering cations }\end{array}$ & 102 \\
\hline$u$ & Bromo-PADAP & $0.5-10049$ & 2 & $\mathrm{Cr} \mathrm{x}^{3+}, \mathrm{v}^{5+}, \mathrm{PO}_{4}^{3-}$ & 103 \\
\hline $\mathrm{U}$ & Tetr apropy lammon i a & $1-100 \quad 19$ & $0.2-2$ & Ce, $\mathrm{Th}$ & $77,104,105$ \\
\hline U & Arsenazo-II I & $1-50 \vee g$ & $1-10$ & Th, Pu, R.E.'s, others & 94,106 \\
\hline $\mathrm{Pu}$ & Tetr apropy lammonia & $1-30 \mathrm{mg}$ & $0.2-2$ & $\cot ^{6+}$ & $82,105,108$ \\
\hline $\mathbf{P u}$ & Pu(III) nitrate & $1.2-18 \mathrm{~g} / \mathrm{L}$ & 0.05 & Differential spectrometry & 109 \\
\hline $\mathrm{Pu}$ & Arsenazo-I & $5-100,119$ & $2-6$ & $\mathrm{U}, \mathrm{zr}$, others & 1.10 \\
\hline
\end{tabular}


The uranyl-nitrate method 95,96 used for in-line process control lacks the precision required for safeguards applications. Browning of the optics can be a serious problem in process streams containing fission products.

3. Plutonium. Most chromogenic reagents that react with plutonium also yield intensely colored species with thorium, uranium, and many fission products; therefore, if plutonium is to be determined in reprocessing samples, a separation is required. For low plutonium concentrations, methods such as alpha or gamma spectrometry may be preferred for measurements.

The tetrapropylammonium method 82 is of interest because uranium and plutonium can be determined sequentially in the same sample. The method has been automated. 105

The differential spectrophotometric method of determining plutonium 109 can be used for plutonium-nitrate product with precision and accuracy equivalent to that obtainable by the best $\in$ lectrometric methods.

C. Electrometric Titration Methods

Both uranium and plutonium can be determined with high precision and accuracy by the use of titrations involving oxidation-reduction reactions. The only oxidation-reduction reaction for thorium involves the $\mathrm{Th}^{0}-\mathrm{Th}^{4+}$ reaction, which has a potential above that for the $\mathrm{H}_{2} \mathrm{O}$ couple. Therefore, thcrium can be determined only indirectly by electrometicic methods.

Eiectrometric methods are classified by the technique used to detect the titration end point, such as potentiometric, amperometric, or coulometric. All of these methods can provide RSDs of better than 0.18 ; hence, for best precision work weight burets should be used in all critical volume measurements.

potentiometric titrations are based on measurement of the change in potential of the system as a component is removed by oxidation or reduction. Because the change in potential is the critical measurement, the accuracy of potentiometric titrations is limited by the sharpness of the potential break at the equivalence point. An RSD of 0.02 to 0.58 is often attainable; 
thelefore, the method is used for measurement of final product such as $\mathrm{U}_{3} \mathrm{O}_{8}, \mathrm{UF}_{6}, \mathrm{PuO}_{2}$, or $\mathrm{Pu}\left(\mathrm{NO}_{3}\right)_{4}$.

Amperometric titrations involve measurement of the change in current between two electrodes that are maintained at a constant potential as titrant is added. The precision of amperometric titrations is limited by the accuracy of the inflection point measurement in the current-titration curve; hence the potential is selected such that the limiting current for reactant, titrant, or product can bo measured, dapending on which yields the sharpest end point. 111

Contiolled-potential and constant-current coulometry are well-established methods for determining uranium and plutonium in solutions. Both methods are based on the principle that the weight of a substance oxidized or reduced at an electrode is proportional to the quantity of e ecuric charge passed through the electrode.lll in controlled-potential coulometry the potential of the electrode is maintained at a constant value relative to a reference electrode to minimize the number of reactions that can take place. Interference from the reactions occurring at lower potentials can be eliminated by performing a preliminary coulometric titration at a potential such that those reactions have occurred before measurements are started. Reactions requiring higher potentials cannot occur. Both urarium and plutonium can be titrated in the same sample withcut separation by performing successive titrations at different potentials. In constant-current coulometry an electrogeneratea reagent reacts with the substance to ve determined.

Coulometric methods can provide RSDs of $0.1 \%$ without the use of chemical standards. Generally, smaller samples usually are required than for potentiometric or amperometric measurements. Coulometric methods have gained increased popularity in recent years, but the determination of plutonium is subject to the following considerations (Ref. 98, p. 250 and Ref. 112). 
- The method is applicable to the determination of plutonium in nitrute product solutions and in dissolver solutions following an anion-exchange separation of fission products.

- The titration can be performed in $1 \mathrm{~N} \mathrm{HClO}_{4}, 1 \mathrm{~N} \mathrm{HNO}_{3}$, $1 \underline{\mathrm{N}} \mathrm{H}_{2} \mathrm{SO}_{4}$, or $1 \underline{\mathrm{N}} \mathrm{HCl}$ electrolytes. However, any $\mathrm{Pu}^{6+}$, if present, is only partially reduced to $\mathrm{Pu}^{3+}$ in $\mathrm{HNO}_{3}$, $\mathrm{HCl}$, or $\mathrm{HClO}_{4} ;$ therefore, $1.0 \underline{\mathrm{N}} \mathrm{H}_{2} \mathrm{SO}_{4}$ is preferred if the sample is believed to contain appreciable $\mathrm{Pu}^{6+}$. Titration in $1.0 \mathrm{~N}_{2} \mathrm{SO}_{4}$ must be performed $\mathrm{i}$ in an oxygenfree atmosphere.

- If iron is present, it is titrated quantitatively in $\mathrm{H}_{2} \mathrm{SO}_{4}$ and a correction must be applied. Iron does not interfere in $1 \mathrm{~N}^{-\mathrm{HClO}_{4}}$ if the plutonium-iron ratio is $>50$.

- If $1 \mathrm{~N} \mathrm{HNO}_{3}$ is used as electrolyte, sulfamic acid must be added to reduce nitrites.

- Polymeric plutonium does not titrate in any case and must be destroyed. Fluorides, used to destroy polyneric plutonium, and organics interfere in all media and must be reinoved.

- Although electrical calibration can be used, for optimum accuracy the instrument should be calibrated using NBS-SRM-Si3d and a correction for isotopic smposition of the sample should be applied.

- Replacement of the platinum electrodes with gold can result in a lower and more reproducible background and an approximately fivefold improvement in precision. 113

- Coulometers may be subject to serious interference from nearby RF generators, such as induction heaters.

1. Thorium. As noted, electrochemical-titration methods generally are not applicable to the direct determination of thorium. Indirect methods involve replacing the electroinactive $\mathrm{Th}^{4+}$ with an electroactive ion during complexometric titration. One such technique, developed for determining thorium in radioactive samples and in the presence of iron, involves the titration of thorium with EDTA using $\mathrm{Fe}^{2+}$ as the electroactive 
ion. 114 The end point is detected amperometrically. The RSD for determining thorium in the presence of uranium, zirconium, and other cations was $2 \%$. An indirect method involving amperometric titration with diphenic acid has been reported to provide an RSD of 0.5\%. Uranium and rare earths do not interfere; incerference from plutonium was not tested. 115

2. Uranium. The electrometric methods for determining uranium rely on the reaction $\mathrm{U}^{4+}-\mathrm{U}^{6+}$ after quantitative reduction of the uranium to the tetravalent state (Ref. 88, pp. 74-83 and 86-88; Refs. 116-119). Differences between methods result from the reduciants and oxidants used. Reducing agenis used to obtain $\mathrm{u}^{4+}$ include zinc amalgam, the Jones reductor, $\mathrm{Ti}^{3+}$, the lead reductor, $\mathrm{r}^{2+}$ in phosphoric acid, and electrical reduction. The Jones reductor can generate a mixture of $\mathrm{U}^{3+}$ and $\mathrm{u}^{4+}$, and the trivalent uranium musi be air-oxidized to the tetravalent state before titration. The reduction with an excess of ferrous ion in ccncentrated phosphoric acid followed by titration with dichromate can be performed in the presence of $\mathrm{Pu}^{4+}$ witholit interference. Some of the standard electrometric techniques for determination of uranium are summarized in Table XII. Of these methods for determining uranium, the Davies-Gray method $116-117$ is the most versatile and has been automated for rapid analysis of process samples (Ref. 88, pp. 77-83 and 86-88; Refs. 117-120).

3. Plutonium. For the electrometric determination of plutonium, the plutonium may be oxidized quantitatively to $\mathrm{pu}^{6+}$, then titrated to $\mathrm{Pu}^{4+}$. This couple is preferred if uranium or iron is present. Oxidants for the first step include Ago and $\mathrm{HClO}_{4}$. If $\mathrm{AgO}$ is used, the excess is destroyed by gentle heating. The oxidation capability of $\mathrm{HClO}_{4}$ is destroyed by diluting the sample after the plutonium has been oxidized. Errors can be introduced into the plutonium measurement if conditions for the dilution are not followed properly. The reduction to $\mathrm{Pu}^{4+}$ uscially is carried out with $\mathrm{Fe}^{2+}$, and can be performed directly or, by using a potentionetric end point, can 
JABLE XII

ELECTROMETRIC METHODS FOR DETERMINING URANIUM

\begin{tabular}{|c|c|c|c|c|c|c|}
\hline Reductant & Oxidant & End Point & Interferences & $\operatorname{RSD}^{a}(8)$ & Sample Size & ReE. No. \\
\hline 2n am.lgam & $\mathrm{K}_{2} \mathrm{Cr}_{2} \mathrm{O}_{7}$ & Colorimetric & Most removed by & 0.62 & $200-300 \mathrm{mg}$ & 118, pp. 74-77 \\
\hline $\begin{array}{l}\mathrm{Fe}^{2+} \\
\mathrm{H}_{3} \mathrm{PO}_{4}\end{array}$ & $\mathrm{~K}_{2} \mathrm{C}=\mathrm{F}_{2} \mathrm{O}_{7}$ & Potentiometric & $\mathrm{Ag}, \mathrm{Hg}$ & 0.07 & $200-300 \mathrm{mg}$ & 115,117 \\
\hline Electrolytic & $\begin{array}{l}\text { Excess } \mathrm{K}_{2} \mathrm{Cr}_{2} \mathrm{O}_{7} \\
\text { back-titrated } \\
\text { with } \mathrm{Fe}^{2+}\end{array}$ & Potentiometric & $\mathrm{Cr}, \mathrm{Fe}, \mathrm{Mo}, \mathrm{Ti}$, & 0.02 & $1-10 \mathrm{~g}$ & 88, pp. $77-83 ;$ \\
\hline $\begin{array}{l}\text { Electrolytic } \\
\text { Pb reductor }\end{array}$ & $\begin{array}{l}\text { Electrolytic } \\
\mathrm{Ce}^{4+}\end{array}$ & $\begin{array}{l}\text { Coulometric } \\
\text { Potentiometric }\end{array}$ & $\begin{array}{l}\mathrm{Fe}, \mathrm{Hg}, \mathrm{Ag}, \mathrm{V} \\
\text { Mo }\end{array}$ & $\begin{array}{c}0.06-0.44 \\
0.03\end{array}$ & $\begin{array}{l}2-20 \mathrm{mg} \\
0.5-1 \mathrm{~g}\end{array}$ & 88, Pp. $86-88 ; 118$ \\
\hline
\end{tabular}

a Generally, the optimum obtainable for fuel process or product samples. 
be sharpened by adding a measured excess of $\mathrm{Fe}^{2+}$ with the excess titrated with $\mathrm{Ce}^{4+}$. Methods involving the $\mathrm{Pu}^{4+}-\mathrm{Pu}^{6+}$ couple are summarized in Table XIII.

Alternatively, plutoniun: can be determined by quantitative reduction to $\mathrm{Pu}^{3+}$ and subsequent ticration to $\mathrm{Pu}^{4+}$ (Ref. 88, pp. 268-299 and 385-388; Ref. 98, pp. 209-212; Refs. 126132). Common reducing agents are liquid zinc amalgam, the Jones reductor, the lead reductor, $\mathrm{Ti}^{3+}, \mathrm{Cr}^{2+}$, and electrical methods. The liquid-zinc-amalgam method suffers in that an extra transfer is required to remove the amalgam before titraricis. Small amounts of titratable material can be leached from the Jones reductor. Fewer elements are reduced with $\mathrm{TiCl}_{3}$ than with the Jones or lead reductors; therefore, there may be fewer potential interferences. ${ }^{127}$ However, $\mathrm{Ti}^{3+}$ is readily destroyed by contact with air.

The oxidation titration to $\mathrm{Pu}^{4+}$ usually is performed electrolytically or with $\mathrm{Ce}^{4+}$ or $\mathrm{K}_{2} \mathrm{Cr}_{2} \mathrm{O}_{7}$. Dichromate has the advantage of being available as a primary standard and it is more stable than $\mathrm{Ce}^{4+}$ over extended storage periods. Uranium and iron interfere with methods involving the $\mathrm{Pu}^{3+}-\mathrm{Pu}^{4+}$ couple. An exception is the controlled-potential coulometric technique in the presence of uranium, and with this method, the two elements can be measured successively in the same sample. ${ }^{28}$ For the controlled-potential coulometric determination of plutonium in dissolver solutions, zirconium must be removed compietely to prevent fouling of the electrode through adsorption of hydrous zirconia. ${ }^{132}$ Methods involving the electrometric determination of plutonium using the $\mathrm{Pu}^{3+}-\mathrm{Pu}^{4+}$ couple are summarized in Table XIV.

D. Polarographic Methods

Polarography is a nontitrimetric analytical electruchemical technique. The voltage between two electrodes immersed in the solution is monitored across a range that includes a redox reaction for the element to be determined. For quiescent solutions 
TABLE XIII

ELECTROMETRIC METHODS FOR PLUTONIUM DETERMINATION USING THE PU(VI)-PU(IV) COUPLE

\begin{tabular}{|c|c|c|c|c|c|c|}
\hline Reductant & Oxidant & End Point & Interferences & $\mathrm{RSD}^{\mathrm{a}}(\mathrm{z})$ & Sample Size & Ref. No. \\
\hline $\mathrm{Fe}^{2+}$ & Ago & Amperometric & $\begin{array}{l}\mathrm{Ce}, \mathrm{Cr}, \mathrm{V}, \mathrm{Mn} \\
\mathrm{Ru}, \mathrm{Au}, \mathrm{Kh}, \mathrm{Pt} \\
\mathrm{Pb}, \mathrm{Am}, \mathrm{Np}\end{array}$ & 0.03 & $10-20 \mathrm{mg}$ & $\begin{array}{l}121,122^{b} \\
128,129\end{array}$ \\
\hline $\begin{array}{l}\text { Excess } \mathrm{Fe}^{2+} \\
\mathrm{Ce}^{4+}\end{array}$ & Ago & Potentiometric & $\mathrm{Ce}, \mathrm{Cr}, \mathrm{V}, \mathrm{Mn}$ & $0.1-0.19$ & $4 \mathrm{mg}$ & $88, \mathrm{pp}, 261-268$ \\
\hline $\begin{array}{l}\text { Excess } \mathrm{Fe}^{2+} \\
\mathrm{K}_{2} \mathrm{Cr}_{2} \mathrm{O}_{7}\end{array}$ & Ago & Potentiometric & $\begin{array}{l}\mathrm{CE}, \mathrm{Ce}, \mathrm{Mn}, \mathrm{V} \text {, } \\
\text { Hu }\end{array}$ & 0.17 & $20-80 \mathrm{mg}$ & 123 \\
\hline $\begin{array}{l}\text { Excess } \mathrm{Fe}^{2+} \\
\mathrm{Ce}^{4 t}\end{array}$ & $\mathrm{HClO}_{4}$ & Potentiometric & $\mathrm{Cr}, \mathrm{Au}, \mathrm{Mn}, \mathrm{Pt}$ & 0.03 & $200-250 \mathrm{sgg}$ & $124^{\circ}$ \\
\hline $\begin{array}{l}\text { Electrically } \\
\text { generated } \\
\text { Ee } 2+\end{array}$ & $\mathrm{KMnO}_{4}$ & Coulometric & $\begin{array}{l}\mathrm{Ag}, \mathrm{Hg}, \mathrm{Ru}, \mathrm{Pd}, \\
\text { Os, } \mathrm{Ce}, \mathrm{Au}, \mathrm{Sn}, \\
\text { (U) }\end{array}$ & 1 & $3 \mathrm{~g}$ to $10 \mathrm{mg}$ & 125 \\
\hline Electrical & Electrical & Coulometric & & 0.1 & $1-10 \mathrm{mg}$ & 112 \\
\hline
\end{tabular}


TABLE XIV

ELECTROAETRIC METHODS FOR PLUTONIUM DETERMINATION USING THE PU(III)-PU(IV) COUPLE

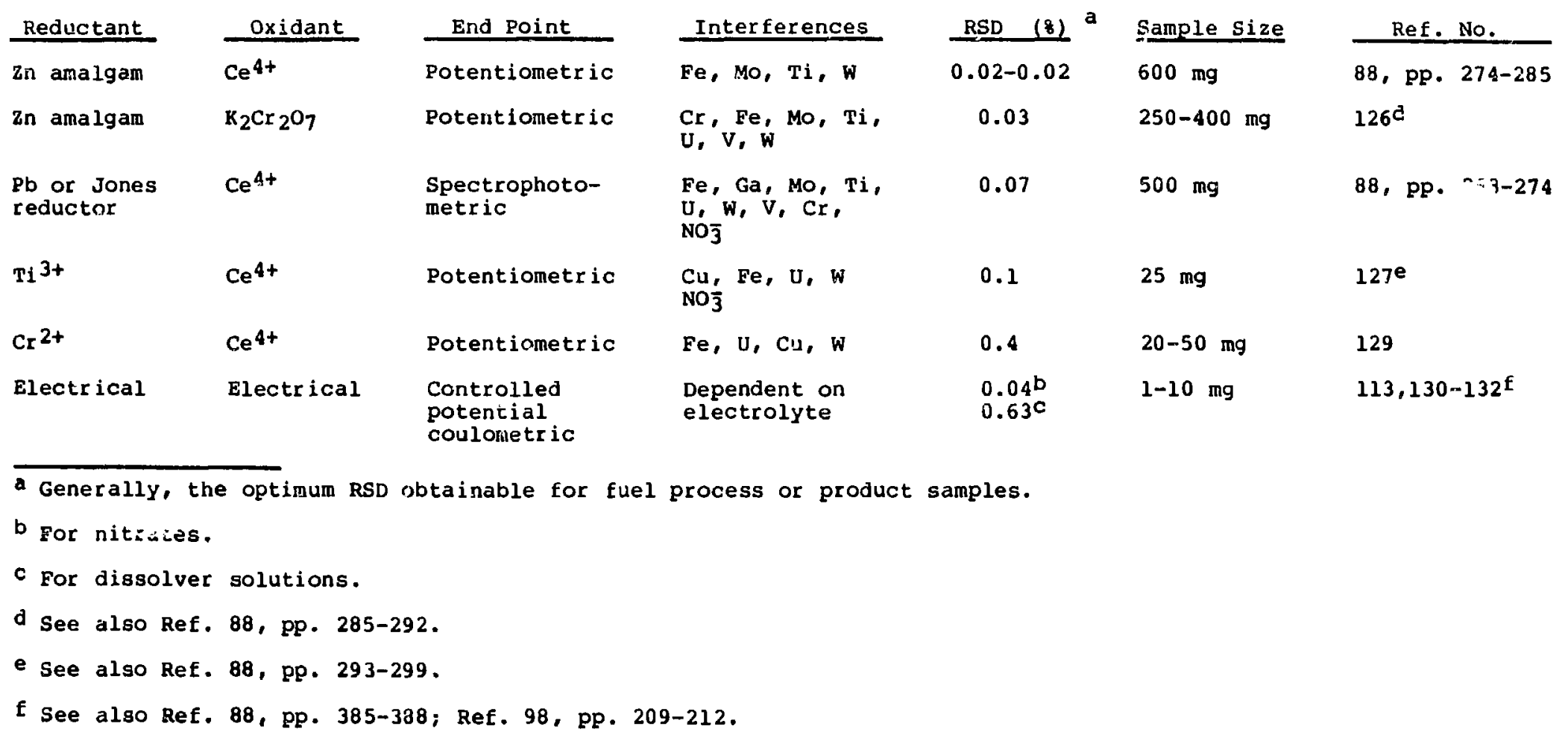


the current, which is diffusion-controlled, is proportional to the concentration. For stirred solutions the relationship is more complex.

The attractiveness of polarography for in-line or at-line analysis lies in the fact that no titrant is required, and analysis can be performed by adding a suitable supporting electrolyte. However, oxygen interferes and must be removed by sparging with an inert gas such as nitrogen or helium.

Polarography has been investigated for the in-line or at-line determination of uranium in reprocessing samples, and the literature is reviewed in Ref. 16, pp. 130-135, and Ref. 133, pp. 151-155. Problems associated with uranium determination by at-line polarography using a dropping-mercury electrode (DME) are reviewed in Ref. 134.

Conventional DME polarography is a diffusion-dependent process and can be used only in a quiescent system. The process sample is circulaied to the sample cell through a bypass line and is allowed to sit after addition of the supporting electrolyte and sparging. Any turbulence caused by pipe variations, sparge lines, or other system malfunctions will affect the results. Interference in uranium determination also results from elements such as molybdenum, copper, or neptunium that are reduced near the uranium reduction potential, 135 ions or molecules adsorbed on the mercury drop, or compounds such as nitrite that increase the reactivity of the mercury.134 Nitrite can be volatilized as methyl nitrite by addition of methanol during the air sparging. 136

Problems associated with the use of mercury can be eliminateó by using a mercury-plated platinum, gold, or graphite electrode. Vibration and other turbulence effects can be eliminated by using rotating electrode techniques. Then, however, the process would no longer be diffusion dependent and empirical calibration must be used, which may be difficult for in-line or at-line analysis. Further development work in this area may be warranted. 
1. Thorium. Direct polarographic methods are not applicable to thorium measurement. Indirect methods that involve electroactive complexing agents such as m-nitrobenzoic acid, m-nitrophenylarsonic acid, or 8-hydroxyquinoline can be applied to pure thorium samples, 137 but are not applicable to reprocessing samples because plutonium, tetravalent ceriun, zirconium, and ruthenium interfere.

2. Uranium. Polarography has been used at Hanford ${ }^{134}$ to measure uranium in reprocessing-plant waste streams in the concentration range 20.01 to $10 \mathrm{~g} / \mathrm{L}$ with $7.5-\mathrm{min}$ analysis times. Although the RSD for synthetic solutions was $28(1 \sigma)$, an RSD of $10 \%$ was obtained for process samples.

In France, early experience wi.th polarography yielded low results for feed and extraction samples containing $>50 \mathrm{~g} / \mathrm{L}$ of uranium, but gave reasonable results for raffinates $\quad<0.5$ $\mathrm{g} / \mathrm{L}) .138$

Polarography using a dilution method has been applied to measurement of uranium in the concentration range 100-200 $\mathrm{g} / \mathrm{L}$ in extraction streams from ore processing. ${ }^{139}$ The dilution error was $0.5 \%$ and the overall RSD was $10.5 \%$. Analyses were obtained at 5 -min intervals.

The technique also has been used in Japan to make measurements in waste streams containing 0.01 to $1 \mathrm{~g} / \mathrm{L}$ of uranium, 140 and in TBP recycle streams containing 0.01 to $0.08 \mathrm{~g} / \mathrm{L}$ of uranium. 141

A cell using two synchronized JMEs as proposed by Lewis and overton $^{143}$ was constructed at SRP ${ }^{157}$ for measuring $10^{-4}$ to $10^{-5} \mathrm{M}$ uranium in flowing streams. Concentrations of $10^{-2} \underline{\mathrm{M}}$ $\mathrm{Fe}^{3+}$ or nitrite, or dissolved TEBP, did not interfere. The maximum period of continuous operation was $8 \mathrm{~h}$. The instrument was not installed in line after the evaluation.

Polarography will be used for determination of uranium in process waste streams at the HTGR reprocessing plant at Julich. 144

3. Plutonium. Square-wave polarography has been investigated for the determination of $10^{-5}$ to $10^{-6} \mathrm{M}$ plutonium. ${ }^{145}$ Iron 
at concentrations five times that of the plutonium concentration interferes seriously in $\mathrm{HNO}_{3}$ solutions. The method probsily is of little value for reprocessing samples.

E. Complexometric Titration

Reagents that form stable complexes with thoilum, uranium, or plutonium can be used in titrimetric analysis provided a suitable end-point indicator is available. If the reagent forms a colored complex or removes a colored compound, the formation or removal of the color can be used for end-point determination. or the end-point indicator may be a dye that forms a colored complex with a slightly lower staility constant than the compound being titrated.

Probably the most commonly used titrant for thorium, uranium, and plutonium is EDTA. Strong complexes are formed; hence, sharp end points can be obtained. The major drawback results from the fact that EDTA complexes with most elements in the periodic chart. Nevertheless, by careful selection of $\mathrm{pH}$ and indicator and by selective complexing of potential interferenres the method is valuable, particularly for the determination of thorium. A RSD of $<0.18$ often can be obtained. Tetravalent actinides also can be titrated with diethylenetriaminepentaacetic acid using xylenol orange as the indicator. 146

1. Thorium. The complexometric determination of thorium with EDTA using various dyes as indicators has been reviewed in Ref. 147, pp. 57-65, and Ref. 15, pp. 184-186. For most of the reagents, titration must be performed at a $\mathrm{pH}<3.5$, above which Th(OH) 4 precipitates. Sulfate, fluoride, oxalate, and phosphate interfere with most of the methods by forming complexes with thorium. Interference by a 500:1 excess of uranium is eliminated by using pyrocatechin violet as the indicator (Ref. 147 , p. 60). When Alizarin Red-s is the indicator, 5-10 $\mathrm{mg}$ of thorium can be titrated with a RSD of 18. Uranium as the uranyl ion ir equal amounts with thorium does not interfere. ${ }^{148} \mathrm{~A}$ similar method has been applied to the successive titration of thorium and uranium in mixed solution using xylenol orange as the indicator. 149 In this procedure the thorium is titrated, 
an excess of EDTA is added, uranium is reduced to $U^{4+}$ with formaldehyde, and the excess EDTA above that required to complex uranium is back-titrated with thorium. Thorium also can be titrated with EDTA in the presence of uranium using Arsenazo as the indicator and diethyldithiocarbamate to mask uranium. 150

Complexometric titration is a primary method for measurement of thorium and should find applications in fuel reprocessing analyses.

2. Uranium. Complexometric titration of uranium with EDTA requires reduction of $\mathrm{UO}_{2}^{2+}$ to $\mathrm{U}^{4+}$. As with the titration of thorium, anions such as sulfate, fluoride, oxalate, and phosphate interfere. The interference of fluoride can be reduced or eliminated by addition of an excess of beryllium.15l Uranium and thorium can be titrated without separation using xylenol orange as an indicator. 149

Complexometric titrations probably offer no advantage over electrometric methods for determining uranium and do not provide equivalent precision.

3. Plutonium. Plutonium forms stable EDTA complexes in both the tri- and tetravalent states, and both have been used for the complexometric titration of plutonium. Trivalent plutonium can be titrated in $\mathrm{HCl}$ media after adjustment of $\mathrm{pH}$ to 2.5.153 When a mixture of Alizarin Red-s and methylene blue was used as an indicator, some interference from the blue plutonium-chloride complex was observed. The end point was sensitive to aging of the sample.

Several indicators can be used to titrate tetravalent plutonium in $\mathrm{HNO}_{3}$ solution. With Arsunazo-I, the titration can be performed in 0.1 to $0.2 \mathrm{~N} \mathrm{HNO}_{3}$ without serious interference from trivalent lanthanides or $\mathrm{UO}_{2}^{2+}$ (Ref. 153.). As expected, thorium interferes quantitatively.

When copper-1-(2-pyridylazo)-2-naphthol (Cli-PAN) is used as an indicator the titration can be performed in $\mathrm{H}_{2} \mathrm{SO}_{4}$ solutions after adjustment of $\mathrm{pH}$ to 2.5-3.0 (Ref. 154). The RSD for determining $14 \mathrm{mg}$ of plutonium is 0.68 . Thorium interferes quantitatively. 
An indirect titration with zinc using ditnizone has been described for determining plutonium in dissolver solutions. 167 The plutonium must be extracted from the bulk of the fission products and uranium. Under carefully controlled conditions $100 \mu \mathrm{g}$ of plutonium can be measured with a precision of $0.48(1 \sigma)$.

F. Mass-Spectrometric Methods

In most existing Purex reprocessing plants thermal-ionization mass spectrometry is used to determine the amount of each isotope of uranium and piutonium and, subsequently, to determine the effective atomic weights used in calculating the total uranium and glutonium from the chemical analysis of accountabilitytank samples. Isotope-dilution mass spectrometry can be used to measure the plutonium and uranium concentrations in the tanks.

Mass spectrometry also can be used in Thorex reprocessing plants to measure thorium as well as uranium and plutonium. The major limitation for measuring thorium measurement results from the lack of suitable NBS-certified standards. For uraiium measurement, ${ }^{235} \mathrm{U}$ rather than ${ }^{233_{U}}$ is proposed as the spike because ${ }^{233_{U}}$ is the major isotope to be measured.

The instrumentation for mass spectrometry is complex and expensive, consisting basically of a source, which is either a single or triple filament; a mass spectrometer: a detector, which is either a Faraday cup or an electron multiplier; and associated control and readout electronics.156,157 Much of the instrumentation can be computer controlled. 158 Singlefilament ion sources require precarburization to provide high metal ion yields, and triple filaments are preferred. The mass spectrometer should have an abundance sensitivity of 100000 or better and a resolution, expressed as $M / \Delta M$, of 400 or greater, where $\Delta M$ is the peak width at 58 of the height above background. For the detector, the Faraday cup provides better measurement accuracy but the electron multiplier yields better sensitivity.

The methods require elaborate sample preparation (Ref. 88, pp. 353-368; Ref. 98, pp. 700-708; Refs. 159-161). A typical 
mass-spectrometric procedure involves (1) dissolving and diluting the sample with $\mathrm{HNC}_{3}$, (2) for isotope-dilution mass spectrometry, spiking part of the diluted sample with accurately known amounts of ${ }^{233} \mathrm{U}$ and ${ }^{242} \mathrm{Pu}$ or ${ }^{244} \mathrm{Pu}$, (3) oxidizing plutonium to the hexavalent state, (4) sequentially separating the fission products, plutonium, and uranium by an anion-exchange procedure or by solvent extraction; and (5) transferring aliquots of the separated uranium and plutonium fractions to separate mass spectrameter fillaments.

Because small amounts of uranium and plutonium $(100 \mathrm{~g}$, and genera?.Iy $<1 \mu$ for plutonium) are to be analyzed, extreme care must be taken in sample preparation and filament loading to avoid contamination by environmental uranium. Determination of ${ }^{238} \mathrm{Pu}$ is particularly sensitive to the presence of ${ }^{238} \mathrm{U}$, and for ${ }^{238} \mathrm{Pu}$ concentrations $<0.7 \%$, alpha-counting methods are preferred. For the measurement of $241_{\mathrm{pu}},{ }^{241_{\mathrm{Am}}}$ must be completeiy separated. For the isotope-dilution mass-spectrometric determination of plutonium, both spiked and unspiked samples must be analyzed to correct for ${ }^{242} \mathrm{Pu}$ in the sample.

Chemical errors may arise also from the presence of high uncentrations of alkali elements. Potassium, in particular, interferes with the measurement of ${ }^{234} \mathrm{U}$ and ${ }^{236} \mathrm{U}$ because of overlap of $\mathrm{K}_{6}$ polymers. Filaments must be checked to ensure that they are free of organics. If organics are detected at ion currents greater than background, the analyses are suspect. ${ }^{162}$

For thermally produced ions the light isotopes are evaporated and ionized preferentially relative to the heavier isotopes of an element. 157 This effect is temperature dependent and is a function or the mass, sample size, and time. It is referred to as the filament bias and must be measured for the instrument every 6 months, and must be controlled as accurately as possible between samples and standards in a series. Temperature can be controlled by direct pyrometer measurement or by adjusting to a constant signal intensity of a filament ion.

Figure 2 show's the precision obtainable by mass spectrometry for different plutonium isotopes.163 A similar curve 


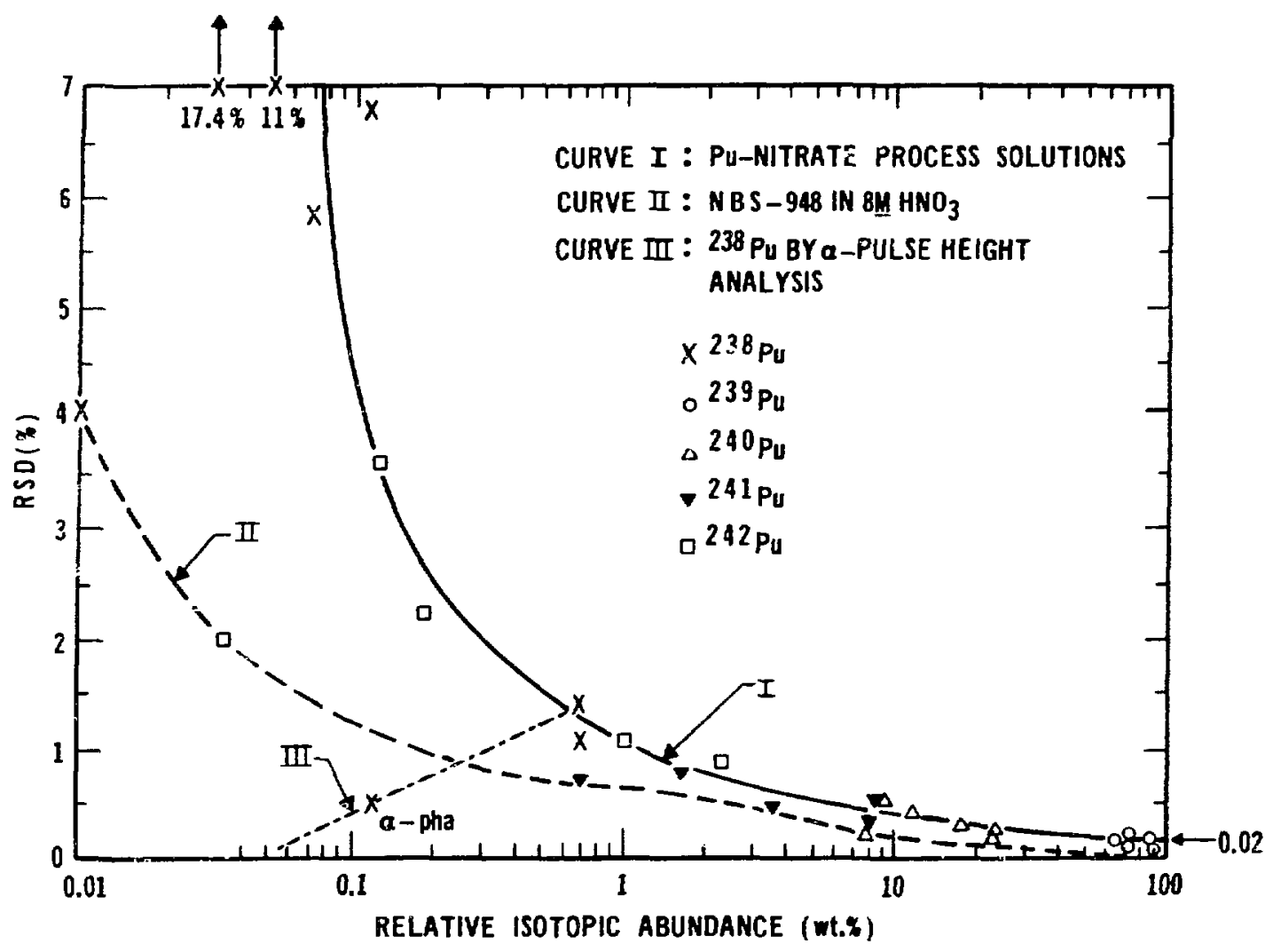

Fig 2. Precision of plutonium isotopic measurement.

applies to uranium isotopic determinations. The figure demonstrates that for major isotopes, RSDs of 0.01 to 0.028 can be attained. The precisions obtained for well-characterized material (a solution of NBS SRM) are significantly better than for the process and product solutions, particularly at isotopic concentrations $>1 \%$. The figure also shows that for measurement of ${ }^{238} \mathrm{Pu}$ concentration $<0.78$ alpha spectrometry is more precise than mass spectrometry. Recent studies show that improvements in precision and accuracy are obtainable if proper care is taken to minimize instrumental and operating errors. In an interlaboratory exchange program an overall RSD of 0.18 was obtained in measuring total plutonium in four samples having different isotopic compositions. ${ }^{164}$ In terms of these data an RSD of 0.1 
to $0.2 \%$ should be obtainable for ineasuring total plutonium in dissolver solutions if careful attention is paid to details of separation chemistry arid instrument operation.

High gamma-radiation levels limit the mass-spectrometric analysis of dissolver solutions to extremely small samples or to samples that have been purified previously in shielded facilities. Microsamples of uranium and plutonium can be obtained on ion-exchange resin beacis for subsequent analysis. ${ }^{165}$ The analytical precision is $<1 z$ (RSD). Alternatively, the mass spectrometer can be modified for analysis of radioactive samples by enclosing the sparking chamber and the initial stage of the flight tube with $10 \mathrm{~cm}(4 \mathrm{in})$ of leaa shielding. ${ }^{16}{ }^{\circ}$ samples emitting up to $100 \mathrm{R} / \mathrm{h}$ of gamma activity can be analyzed in this fashion.

Mass spectrometry currently provides the most accurate isotopic analysis, even in the presence of fission products. The isotope-dilution method provides overall accuracy of $0.3-1$ for for the measurement of total uranium and plutonium concentrations in dissolver solutions. However, Teledyne Isotopes qualified for a uranium analysis in thorium-uranium fuels with an overall measurement error (isotopic plus total uranium) of 0.128 . This more nearly represents the state of the art. ${ }^{167}$ The control of sample preparation is crucial to the accuracy. Even under ideal experimental conditions some $10 \%$ of the plutonium assays had to be discarded, probably because of poor sample preparation. G. Alpha-Spectrometric Methods

Quantitative alpha-particle spectrometry is based on measurement of the alpha-radiation intensity of the sample. The alpha particles are ejected with discrete energies, and for the uranium, neptunium, plutonium, and americium isotopes found in the nuclear fuel cycle these energies range from 4 to $5.5 \mathrm{MeV}$. Alpha-particle energies are rapidly degraded by interactions with electrons, and complete attenuation is effected by $25 \mathrm{~cm}$ of air. Absorption by $\mathrm{H}_{2} \mathrm{O}$ and self-absorption by the sample are even more rapid: and normal quantitative alpha spectrometry is limited to analysis of thin, dry films. The method has been 
applied to letermiration of plutonium in dissolver solutions following solvent-extraction separation of the plutoniun (Ref. 81; Ref. 88, pp. 392-398;. The RSD for dissolver samples is in the range $3-5 \%(l \sigma)$. The method also is used for determining plutonium in uranium product and process waste streams. lóg

Because of the long half-lives of the major isotopes and possible interEerence Erom other alpha emitters such as neptunium, plutonium, and americium, the method probably is not applicable to thorium or uranium analysis.

Deteators used for alpha spectrometry incluae standard raảiation instrument.s such as proportional counters, scintillation detectors, and solid-state devices. Special techniques have been developed for alpha-counting of purex process streams, where the detector must be in direct contact with the alpha radiation sources. 170-174 Performance requirements are severe. The detector must operate in a flowing-liquid envirorment that is often of high acidity; it must be corrosion- and abrasionresistant; it should discriminate alpha signals in the presence of nigh beta-gamma fluxes from fission products; and it should be insoluble in organics. originally, Zns(Ag) scintillation detectors were usea, but were too fragile and difficult to fabricate. Organic scintillators in general cannot withstand the liquid environments. A cerium-activated vycor glass detector has been developedill that will operate for months in a Purex process stream. The stopping distance for $5-\mathrm{MeV}$ alpha particles in Vycor glass is estimated to be $25 \mu \mathrm{m}$, whereas beta particles of energies $>0.5 \mathrm{MeV}$ llave penetration thicknesses in excess of $900 \mu \mathrm{m} .173$ 'rinus, by reducing the cerium-activated layer to the alpha-particle penetration thickness, the alpha particles can be stopped in the active layer while most of the high-energy betas will pass through undetected. A further decrease in beta interference is attained by using thin sample cells, 175 and electronic pulse-shaping circuitry.176

The instruments can measure plutonium solutions in the concentration range between $10^{-4}$ and $1 \mathrm{~g} / \mathrm{L}$ in the presence of beta-gamma fields up to $10^{8}$ dis/min-mL. 177 Deviations from 
linearity at low plutonium concentrations $\left(<1 \mathrm{~J}^{-3} \mathrm{~g} / \mathrm{L}\right)$ are caused by plating on the detector window and at high plutonium concentrations (>0.1 $\mathrm{g} / \mathrm{L})$ are caused by pilse pile up. Interference results from large variations in sample density that cause self-attenuation problems and from the presence of other alpha enitters such as neptunium, ameliciuin, or uranium. Calibration is performed empiricaliy for each stream by chemical anaiysis.

The method still is being evaluated to measure its tolerance for beta and gamma emitters and to assess its applicapility to in-line analysis. 178

Diamond detectors recently were investigated as in-line alpha monitors, but data for process operation in the presence of high beta-gamma fluxes are not available. 179

H. Fluorimetric Methods

The fluorimetric determination of low concencrations of uranium is based on the fluorescence of uranium when it is excited by ultraviolet light. The Eluorescent spectrum consists of four bands in the visible region, with the most intense band at $554.6 \mu \mathrm{m}$. With $365-\mu \mathrm{m}$ excitation from a high-intensity mercury lamp, few other elements will interfere by fluorescence.

Samples are evaporated and fused in a carbonate Elux containing 10\% NaF (Ref. 180) or NaF flux and sometimes containing LiF (Ref. 181) or some carbonate. Carbonate fluxes are easier to handle and provide better analytical precision. Fluoride fluxes provide better sensitivity but are more sensitive to variations in flux temperature and cooling conditions.

Although few elements or compounds have overlapping fluorescence spectra that interfere with the method, a number of elements interfere through quenching or enhancement. Quenching can result from absorption of the incident light, absorption of the fluorescent light, interference with the energy-transfer paths at phosphor centers, or precipitation of uranium. 17,182

Most of the transition elements interfere to some degree through quenching. With a flux of $98 \%$ NaF-2\% LiF, serious quenching is observed in the presence of small amounts of 
cadmium, chromium, cobalt, copper, iron, magnesium, manganese, nickel, lead, platinum, silicon, thorium, and zinc. Niooium and tantalum enhance the uranium fluorescence (Ref. 98, pp. 588594). Many of the interferences can be removed by a combination of precipitation and solvent extraction of the uranium into ethyl acetate (Ref. 88, pp. 232-237) or into methyl-isobutyl ketone containiny tetrapropylammonium nitrate. Alternatively, quenching interference can be minimized by comparing the measured fluorescence from a fused button of the sample and a similar button containing a known added amount of uranium (spiking).

As little as $1 \mathrm{ng}$ of uranium can be detected by the fluorimetric method. The RSD for measuring uranium in simulated reprocessing-plant waste streams is reported to be $13 \% .183$

I. Specific-Ion Electrodes

Specific-ion-sensitive electrodes have been studied for several years both for process control and analytical end-point detection. The applications of ion-selective electrodes to online analysis have been reviewed. 184 Although electrodes are not specific for thorium, uranium, and plutonium because all three are expected to behave similarly in the tetravalent state, the tecrnique has elicited some interest, particularly for the determination of uranium.

The theory and applications of ion-sensitive electrodes have been discussed extensively.185-188 The technique is based on the Nernstian response of an electrode pair (one electrode is sensitive to the ion measured and the second electrode j.s $a$ reference) to the ion activity (or concentration) of the element determined. The measuring electrode incorporates the element to be determined in some form that is responsive to the activity or concentration in solution.

1. Thorium. Most solid ion-selective elertrodes are sensitive to mono- and divalent cations. Liquid ion-exchange membranes using dinonyl-napthalenesulfonic acid (DNNS) electrojes have been developed that are sensitive to tri- and tetravalent cations, including thorium. 189 The response is near Nernstian but selectivity is poor. 
2. Uranium. Several attempts have been made to form uranium-sensitive electrodes. An electrode based on a uranyl complex of an organophosphoric acid embedded in a polyvinyl chloride matrix was patented in 1975.190 A number of organophosphorus complexes subsequently were studied for possible application as uranium-ion sensors. 191 several sensors showed near-Nernstian response and linearity to uranium concentration in the range $10^{-1}$ to $10^{-4}$ M. The optimum $\mathrm{pH}$ range was $2-3.5$. The membranes were poisoned by $\mathrm{Fe}^{3+}$. Solid-state electrodes fabricated from uranium alloyed with titanium, molybdenum, or niobium gave a linear response proportional to urariurn concentration, but sensitivity was poor. 192 Electrodes of $\mathrm{UO}_{2}{ }^{\prime} \mathrm{U}_{3} \mathrm{Si}_{2}$ ' $\mathrm{US}_{2}$, UC ${ }_{2}$, and UP did not respond. Membrane electrodes also were studied, but response to uranium concentration was low and erratic.

Additional work on uranium-sensitive electrodes may be warranted for on-line or at-line measurement of low concentrations of uranium.

3. Plutonium. Plutonium-sensitive electrodes have not been studied, and probably would be of questionable value because other more sensitive methods for measuring plutonium are available.

\section{J. X-Ray Fluorescence Techniques}

X-ray fluorescence techniques have been applied to the analysis of actinide solutions for over 25 years. They are sensitive and accurate and, with appropriate separation and samplepreparation schemes, are capable of measuring microgram quantities of material to relative accuracies of 18 or less. Typical analysis times are short $(0.5 \mathrm{~h}$ or less). The fundamentals of $x-r a y$ fluorescence analysis have been reviewed in detail in the literature. 193-196 The analyst has considerable latitude in selecting a technique, including choices of excitation source, detector, and $x-r a y ~ l i n e$.

The most commonly used excitation source is the $x-r a y$ generator because of its high flux, alinough the use of radioisotopes 
is becoming more common because solid-state detectors are available and can detect the lower, secondary $x$-ray levels. x-ray tubes generally are required when wavelength-dispersive spectrometers are used (because of the low spectrometer efficiencies) and when radioactive solutions from spent flils are measured (because the signal generated by the excitation source must be greater than that caused by the fission products). When they are applicable, radioisotopic sources 197,198 (such as ${ }^{125} \mathrm{I}$, ${ }^{109} \mathrm{Cd}$, and secondary targets fluoresced with $241_{\mathrm{Am}}$ ) offer advantages such as ease of measurement configuration, long-term stability, and lower cost.

Both wavelength- and energy-dispersive detection systems have been used to measure thorium, uranium, and plutonium in solution. Wavelength dispersion offers bigh resolution, but at low efficiencies. Energy dispersion is more efficjent but has poorer resolution at energies $<20 \mathrm{keV}$. At energies $>20-25 \mathrm{keV}$, a $\mathbf{S i}(\mathrm{Li})$ energy-dispersive spectrometer provides better resolution and eficiency. The high resolution of wavelength-dispersive spectrometers is an asset in the measurement of spent fuels where there is a potential for interference from the multitude of fission products. The high efficiency of energy-dispersive, solid-state $\mathrm{Ge}(\mathrm{Li})$ detectors is often an asset in measurements of "cold" solutions when radioisotopic excitation sources are used.

1. Selection of a Line. For thorium, uranium, and plutonium measurements, lines in the $K, L$, or $M$ series can be used; the more intense lines in these series are summarized in Table $x V$. When selecting a line to use in an $x$-ray fluorescence measurement, the main considerations are line intensity above background and interferences from adjacent lines.

The high energies of the K-series lines require either the use of generators and $x$-ray tubes capable of producing up to 150-kev $x$ rays, or the use of gamma-ray excitation sources. Diffraction gratings or crystals that provide good dispersion in 
TABLE XV

X-RAY LINES COMMONLY USED FOR URANIUM AND PLUTONIUM

\begin{tabular}{lrrr} 
Line & \multicolumn{3}{c}{ Energy (keV) } \\
\cline { 2 - 4 } $\mathrm{K} \alpha$ & Thorium & Uranium & Plutonium \\
$\mathrm{K} \beta$ & 93.350 & 98.440 & 111.303 \\
$\mathrm{~L} \alpha_{1}$ & 105.609 & 103.763 & 117.256 \\
$\mathrm{~L} \alpha_{2}$ & 12.969 & 13.612 & 14.276 \\
$\mathrm{~L} \ell$ & 12.810 & 13.437 & 14.082 \\
$\mathrm{~L} \beta_{1}$ & 11.119 & 11.616 & 12.122 \\
$\mathrm{~L} \beta_{2}$ & 1.6 .202 & 17.217 & 18.291 \\
$\mathrm{~L} \gamma_{1}$ & 15.624 & 16.428 & 17.255 \\
$\mathrm{M} \alpha$ & 1.8 .902 & 20.164 & 21.414 \\
$\mathrm{M} \beta$ & 2.993 & 3.167 & 3.356
\end{tabular}

this energy region are not available, so energy-dispersive systems must be used. In addition, there may be significant orerlap of plutonium gamma rays with the uranium and plutonium $x$ rays. Nevertheless, K-series $x$ rays have been applied to solution analysis. 199 Use of the M-series $x$ rays requires either a helium or vacuum path to minimize air absorption, and use of these lines usually is limited to solias. Because of the close proximity of the thorium, uranium, and plutonium lines, wavelength-äispersive systems must be used. Even then, serious problems can result from the overlap of the $M \alpha$ and $M \beta$ lines of plutonium by the $M \beta$ and $M \gamma$ lines, respectively, of uranium and of the $M \alpha$ and $M \beta$ lines of uranium by the $M \beta$ and $M \gamma$ lines of thorium. Nevertheless, M-series lines have been ured for some types of analyses. 200 
The most common choice is one or more of the $L$ lines. They provide good intensities in an air path for analyses of solutions or solids, and can be used with any type of excitation or detection system.

2. Interferences. Three types of matrix interference are encountered in $x$-ray fluorescence: line overlap, absorption, and enhancement.

Line interference occurs when a matrix element has an emission line that overlaps that of the special nuclear material (SNM). In the 11 - to $20-\mathrm{keV}$ energy region, the elements from arsenic to molybdenum have one or more strong $\mathrm{K}$ lines that are close enough in energy to the commonly measured $L$ lines of thorium, uranium, and plutonium to be a possible source of interference. Unfortunately, many of these elements appear as fission products in spent fuel.

Absorption and enhancement are essentially two mani.estations of the same phenomenon. Absorption, which occurs in a rying degrees in all samples, is the more serious of the tw Both the matrix and the SNM can attenuate the SNM line, causing a negative bias in the assay result. Matrix enhancement occurs if a matrix element has a strong $x$-ray line above the energy of the absorption edge of the SNM analyte. For example, if molybdenum is present in a uranium solution, the molybdenum $\mathrm{K} \alpha_{I}$ line can excite the uranium $L \alpha$ lines and cause a positive bias in the uranium measurement. For uranium and the transuranics, self-enhancement also can occur.201 for these elements, the $L \beta_{1}$ emission line is above the $L_{I I I}$ absorption edge in energy and can excite the $I$ lires commonly used for measurement. Self-enhancement is generally not noticeable unless large quantities of uranium and plutonium are present.

The internal-standard method corrects for matrix absorption-enhancement effects by adding a known standard to the solution and comparing the counts in the SNM line to the counts in the standard line. The standard line is chosen as close to the analyte line as possible, preferably with an absorption edge 
above the energy of any enhancing matcix lines. Different internal standards, including strontium for aqueous solutions and bromobenzene for organic solutions, have been used in the measurement of thorium and uranium at different stages of solvent extraction. 202 Zirconium also has been sugsested as an internal standard for organic uranium and thorium solutions. 203

Thorium is the commonly used internal standard for uranium and plutonium solutions, 203-205 but yttrium also is used 206 when the possibility of thorium contamination exists in the sample, as would be the case for Thorex reprocessing samples.

Another matrix-correction technique, the scattered $x$-ray method, primarily corrects for matrix absorption but not, in general, for enhancement. Thus, its application is best suited to process-control situations where matrix properties are well known and nonvariable. In this method, instead of adding lines to the spectrum by adding a standard to the solution, a scattered $x$-ray line is used as a standard. The compton-scatterea molybdenum $k \alpha$ line has been used to measure plutonium in solutions of plutonium-aluminum alloys 207 and the incoherently scattered iodine $\mathrm{K} \alpha$ line has been used to measure uranyl nitrate solutions. 208 These authors report that the technique could extend the range of measurable concentrations up to $500 \mathrm{~g} / \mathrm{L}$ of uranium.

A novel scattering technique has been reported ${ }^{209}$ that can rapidly measure uranium concentrations of 1 to $10 \mathrm{~g} / \mathrm{L}$ in the presence of high concentrations of low-z matrix elements. Instead of measuring an SNM line, coherent (Rayleigh-scattered) radiation is measured at appropriate angles. The method is not completely matrix-compensating; the addition of $60 \mathrm{~g} / \mathrm{L}$ of aluminum to an $8 \mathrm{~g} / \mathrm{L}$ uranium solution increased the uranium measurement by $1 \mathrm{~g} / \mathrm{L}$. In situations where matrix concentrations are known to fluctuate by only à few per cent, Mccue et al. 209 claim that accuracies of $0.7 \%$ or better are possible in short counting times. 

fluorescence measurements of SNM solutions have had wide exposure in the literature, current safeguards applications are limited because of competition from other less complex and less matrix-dependent methods. To reduce the matrix sensitivity, samples are often evaporated as thin films. This technique reduces the scattered background compared to the sample signal, thus increasing sensitivity and reducing counting times. 210 Measurements of thin films are linear with the concentration of SMM over a small range, above which saturation effects become important.

Several systems have been developed to assay highly radioactive spent-fuel solutions. One of these systems $203,204,211$ uses a wavelength-dispersive spectrometer to assay solutions having uranium-plutonium ratios of from $50: 1$ to $300: 1$ with accuracies of $\sim 1 z(1 \sigma)$ in $2-5 \mathrm{~min}$. Solutions having activities of $<1 \mathrm{Ci} / \mathrm{mL}$ are handled routinely by evaporating small samples onto a filter paper. Samples having low heta-gamma activities can be analyzed directly in solution after addition of an internal standard. The fission products cause no serious line interference. An automatic sample-preparation system is being developed to allow on-line analysis.

Uranium and plutonium in solution having beta-gamma activities to $1 \mathrm{Ci} / \mathrm{L}$ have been measured directly through a Plexiglas window. 206 The system used is as close to in-line analysis as one can devise. An automatic sampler removes solutions from the sample line and yttrium is added to serve as an internal standard. Solution transfers are made by pneumatic tube. A minicomputer performs data reduction, and overall precision and accuracy of better than $1 \%$ are claimed for the technique.

In another system, 212,213 hot dissolver solutions containing uranium and plutonium at ratios up to $400: 1$ and uranium concentrations of $\sim 50 \mathrm{~g} / \mathrm{L}$ are measured with an $\mathrm{x}$-ray tube in combination with a $S i(I-i)$ detector. Preliminary tests indicate that accuracies of $1-28$ are possible with $10-$ min analysis times. 
However, accuracies of only 38 are obtained because of problems in sample preparation. A new preparation method now being evaluated should improve measurement accuracy.

A system has been developed for automatic sampling and sample preparation of dissolver solutions from the reprocessing of thorium-uranium fuels. 203 For solutions emitting up to $2000 \mathrm{Ci} / \mathrm{L}$, samples containing $1.0 \mathrm{ml}$ of solution are automatically aliquoted and mixed with an internal standard. The aliquots are evaporated onto a filter paper, whicin is transferred to a shielded $x$-ray spectrograph. All operations are performed remotely under computer control.

Thorium and uranium have been measured directly in solution by using strontium as an internal standard. ${ }^{214}$ The method yields a RSD of $1.58(1 \sigma)$ in the concentration range 0.1 to $10 \mathrm{~g} / \mathrm{L}$ but probably cannot be applied to highly irradiated samples.

\section{PROBLEM AREAS}

The sample selected for analysis must be representative of the bulk material being sampled. In Thorex or Purex reprocessing systems several effects can alter the sample sufficiently to negate the most carefully conceived and administered analytical plans. The high radiation fields in the samples can cause sample heating, solvent decomposition, reagent degradation, and oxidation-reduction reactions. This is particularly true at the dissolver end of the stream where high concentrations of fission products result in intense beta-gamma fields and at the plutonium product end where high alpha-radiation levels are present. The high gamma fluxes associated with reprocessed thorium and ${ }^{233} \mathrm{U}$ product streams require that all analytical manipulations be performed remotely in shielded facilities.

Analytical problems associated with sample heat, radiolytic decomposition of reagents, polymerization, and radioactive sample decay have been summarized.215-217 Problems in sampling and sampie storage associated with high gamma fluxes will persist through the thorium and uranium storage areas of Thorex 
reprocessing because of the radiation from thorium and uranium decay products.

\section{SUMMARY AND CONCLUSIONS}

The analytical chemical needs in a piant designed to reprocess thorium-uranium fuels will require highly precise and accurate measurements of uranjum as well as plutonium. The ${ }^{233} \mathrm{U}$ (and ${ }^{235} \mathrm{U}$ for first-generation reactor fuel) must be measured with the same care given to plutonium. For fuels diluted with ${ }^{238} \mathrm{U}$, significant quantities of weapons-grade plutonium will be produced and must be measured accurately.

Isotope-dilution mass spectrometry will contiñue-to be a key accountability measurement for both uranium and plutonium in dissolver solutions, not only because of its potential for high precision and accuracy but because isotopic analyses can be correlated with reactor data. Thorium also can be measured by using a ${ }^{230} \mathrm{Th}$ spike. Electrometric methods for uranium ana plutonium measurement will be required for calibration checks of NDA instruments. Plutonium product also can be measured by electrometric titrations. In-line alpha monitors for plutonium and in-line polarography for uranium may be developed for wastesiream measurements but will be supplemented by spectrophotometric and fluorimetric methods for calibration checks.

Thorium, though not an SNM, must be measured for accountability checks and to meet NRC and IAEA requirements. Gravimetry and EDTA titrations probably will be the methods of choice. For thorium product measurements, analyses must be adapted to hotcell operation. The process of radioactive decay cannot be ignored in the analytical scheme nor can the influence of thorium content on the analyses of the fissile materials.

Automation of instrumentation for remote operation will be necessary for many routine analyses because of the high radiation levels associated even with purified uranium and thorium product streams. Much work already has been done in this direction, including the automated spectrophotometer for uranium and 
plutonium analyses, 105 potentiometric determination of uranium, 117 controlled-potential coulometric determination of uranium and plutonium, 218 mass-spectrometric determination of uranium and plutonium, 168 and $x$-ray fluorescence analysis of all three elements. 203-206,211,212 Remote-sampling techniques $^{203}$ and small-sample methods such as the resin-bead 165 will be important to minimize personnel exposure. In-line methods will be required not only for near-real-time accounting but also for minimizing exposure to personnel. 


\section{ACKNOWLEDGMENTS}

The author gratefully acknowledges the helpful suggestions and criticism of R. J. Dietz, D. D. Cobb, H. A. Dayem, C. A. Ostena': and J. P. Shipley of the Q-4 staff; J. R. Phillips of Q-1; G. R. Waterbury of CMB-1; J. A. Goleb of the office of Safeguards and Security, DOE; C. D. Bingham of the New Brunswick Labortory; T. L. Williams of Allied-General Nuclear Services; R. S. Swingle II anci E. Lukosius of the Savannah River Laboratory; W. Lawless, DOE/SRO; and L. Abraham, G. E. Benedict, H. C. Carney, N. D. Holder, E. M. Knox, J. J. Shefcik, and R. G. Wilbourn of the General Atomic Company. The manuscript was prepared by Sharon Klein. 
1. I. E. Rushton, J. D. Jenkins, and S. R. McNeany, "Nondestructive Assay Techniques for Recycled $23^{3} \mathrm{U}$ Fuel for High-Temperature Gas-Cooled Reactors," Nucl. Mater. Manage. IV(1), 18-35 (1975).

2. Department of Energy Working Task Group, "Barnwell Nuclear Fuels Plant Applicability Study, Vol. III, Appendices," Department of Energy report DOE/ET-0040/3 (March 1978).

3. K. H. Lin, "Characteristics of Radioactive waste Streams Generated in H'TGR Fuel Reprocessing," Oak Ridge National Laboratory report CRNL-TM-5096 (Janliary 1976), p. 5 .

4. A. L. Lotts and P. R. Kasten, "Gas-Cooled Reactor Programs, Thorium Utilization Program Progress Report, July 1, 1975September 30, 1976," Oak Ridge National Lakoratnry report ORNL-5260 (July 1977), p. 35 .

5. "Thorium Utilization Program, Quarterly Progress Report for the Period Ending February 28, 1977," General Atomic Co. report GA-Al4304 (March 1977), p. 11-4.

6. "Barnwell Nuclear Fuels Plant Separations Facility--Final Safety Analysis Report," Docket 50-332, Allied-Genera? Nuclear Services, October 10, 1973.

7. J. I. Bramman, R. M. Sharpe, D. Thom, and G. Yates, "Metallic Fission-Product Inclusions in Irradiated Oxide Fuels," J. Nucl. Mater. 25, 201-215 (1968).

8. K. H. Lin and W. E. Clark, "High-Level Solid Wastes from HTGR Fuel Reprocessing," Oak Ridge National Laboratory report GCR-77/10 (August 1977). Presented at the 1977 winter Meeting of the ANS, San Franciscr, California, November 27-December 2, 1977.

9. Analytical Methods Committee, International Union of Pure and Applied Chemistry, "Sodium Carbonate as a Primary Standard in Acid-Base Titrimetry," Analyst 90, 251-255 (1965).

10. National Burealu of Standards, "Catalog of NBS Standard Reference Materials," NBS Special Publ. 260 (1975).

11. F. B. Stephens, R. G. Gutmacher, K. Ernst, J. E. Harrar, and S. P. Turel, "Methods for the Accolintability of Uranium Dioxide," US Nuclear Regulatory Comsission report NUREG75/010 (June 1975), p. 5-17. 
12. K. F. Lauer and Y. LeDuigou, "Proper lise of Reference Materials for the Accurate Determination of Uranium, Plutonium, and Thorium in the Nuclear Fue? Cycle," in Analytical Methods in the Nuclear Fuel Cycle, Proc. Symp., Vienna, November 29-December 3, 1971 (Ir.ternational Atomic Energy Agency, Vienna, 1972), pp. 145-15?.

13. J. E. Rein, S. F. Marsh, G. C. Svanson, G. R. Waterbury, G. L. Tietjen, and R. ř. Ziegler, "Preparation of working Calibration and Test Materials: Plutonium Nitrate Solution," Los Alamos Scientific Labcratory and US Nuclear Regulatory Commission report IAA-NUREG-6348 (January 1977).

14. V. Wenzel and H. J. Riedel, "Actinide Composition Studies on Thorium/Uranium Fuel Elements with Known Irradiation Data," in Analytical Methods in the Nuclear Fuel Cycle, Proc. Symp., Vienna, November 29-December 3, 1971 (International Atomic Energy Agency, Vienna, 1972), pp. 549-562.

15. F. S. Grimaldi, "Thorium," in Treatise on Analytical Chemistry, I. M. Kolthoff and P. J. Elving, Eds. (Interscience Publishers, New York, 1961), Part II, Vol. 5, pp. 159-164.

16. H. Sorantin, Determination of Uranium and Plutonium in Nuclear Fuels (Verlag Chemie, Weinheim, Germany, 1975), pp. 68-71.

17. G. L. Booman and J. E. Rein, "Uranium," in Treatise on Analytical Chemistry, I. M. Kolthoff and P. J. Elving, Eds. (Interscience Publishers, New York, 1961), Part II, Vol. 9, pp. $1-188$.

18. C. F. Metz and G. R. Waterbury, "The Transuranic Elements," in Treatise on Analytical Chemistry, I. M. Kolthoff and P. J. Elving, Eds. (Interscience Pubilishers, New York, 1961), Part II, Vol. 9, pp. 189-440.

19. M. S. Milyukova, N. I. Gusev, I. G. Sentyurin, and I. S. Sklyarenko, Analytical Chemistry of Plutonium (Ann Arbor-Humphrey Science Publishers Ann Arbor, 1969).

20. J. Korkisch, Modern Methods for the Separation of Rarer Metal Ions (Pergamon Press, Oxford, 1969), pp. 28-196.

21. J. Faris and R. F. Buchanan, "Anion Exchange in Nitrate Solutions," in progress in Nuclear Energy, series IX, Analytical Chemistry, Vol. ó (Pergamon Press, oxford, 1966), p. 147-180. 
22. J. Korkisch, "Ion Exchange in Mixed and Non-Aqueous Media," in Progress in Nuclear Energy, Series IX, Analytical Chemistry, Vol. 6 (Pergamon Press, oxford, 1966), pp. 1-94.

23. J. Korkisch and F. Tera, "Ionenaustausch in Losungsmittelgemischen. III. Uber die Verteilung des Thoriumchlorids $\mathrm{Zwischen}$ Seinen Alkoholischen Salzsauren Losungen und Stark Basischen Anionenaustauschern," J. Inorg. Nucl. Chem. 15, 177-181 (1960) (in German; English abstract).

24. S. Urubay, G. E. Janauer, and J. Korkisch, "Anion Exchange of Uranium and Thorium in Ketone Media," $z$. Anal. Chem. 193, 165-171 (1963).

25. S. F. Marsh, J. E. Alarid, C. F. Hammond, M. J. MCLeod, F. R. Roensch, and J. E. Rein, "Anion Exchange of 58 Elements in Hydrobromic Acid and in Hydriodic Acid," Los Alamos Scientific Labortory report LA-7084 (February 1978).

26. E. Akatsu and H. Watanabe, "Ion Exchange of 36 Elements with DIAION PA306," Anal. Chim. Acta 93, 317-322 (1977).

27. C. B. Amphlett, Inorganic Ion Exchangers, (Elsevier Publishing Company, New York, 1964).

28. F. Girardi, R. Pietra, anä E. Sabbioni, "Radiochemical Jeparations by Retention on Ionic Precipitate Absorption Tests on 11 Materials," J. Radioanal. Chem. ${ }_{5}$, 141-171 (1970) "

29. G. J. Moody and J. D. R. Thomas, "Inorganic Ion Exchange in Organic and Aqueous-organic Solvents, A Review," Analyst 93, $557-588$ (1968).

30. I. Gal and A. Ruvarac, "The Separation of Plutonium from Uranium and Fission Products on Zirconium Phosphate Columns," J. Chromatogr. 13, 549-555 (1964).

31. S. Ahrland, I. Grenthe, and B. Noren, "The Ion Exchange Properties of Silica Gel. II. Separation of Plutonium and Fission Products from Irradiated Uranium," Acta Chem. Scand. 14, 1077-1090 (1960).

32. J. Korkisch and S. S. Ahluwalia, "Cation-Exchange Behaviour of Several Elements in Hydrochloric Acid-Organic Solvent Media," Talanta 14, 155-170 (1967).

33. T. Murase, E. L. Lind, and F. Nelson, "Ion Exchange Procedures. IV. Separation of $234_{\mathrm{Th}}\left(\mathrm{UX}_{1}\right)$ from Uranyl Nitrate Solutions," J. Chromatogr. 14, 478-481 (1964). 
34. J. Korkisch and F. Tera, "The Distribution of Hexavalent Uranium and Tetravalent Thorium Between Alcohol-Nitric Acid Solutions and the Strongly Acidic Cation Exchanger Dowex-50. Separation of Uranium from Thorium," J. Chromatogr. 8, 516-521 (1962).

35. C. W. Sill, "Preparation of Carrier-Free Thorium-234 Tracer," Anal. Chem. 36, 575-676 (1964).

36. J. Danon, "Separation of Thorium and Rare-Earth Elements in Nitric Acid Media by Anion Exchange," J. Inorg. Nucl. Chem. s, 237-239 (1957).

37. J. Korkisch and 5. S. Ahluwalia, "Anion Exchange Separation of Thorium from the Rare Earth Elements in an AcetoneNitric Acid Medium," J. Inorg. Nucl. Chem. 28, 264-266 (1966).

38. J. S. Fritz and B. B. Garralda, "Anion Exchange Separation of Thorium Using Nitric Acid," Anal. Chem. 34, 1387-1389 (1962).

39. F. W. E. Strelow and C. J. C. Bothma, "Anion Exchange and a Selectivity Scale for Elements in Sulfuric Acid Media with a Strongly Basic Resin," Anal. Chem. 39, 595-599 (1967).

40. F. W. E. Strelow, "Separation of Uranium from Scandium, Yttrium, Rare-Earth Elements, Thorium, Beryllium, Magnesium, Copper, Manganese, Iron, Aluminum, and Other Elements by Cation-Exchange Chromatography," J. S. Afr. Chem. Inst. $16,38-47$ (1963).

41. J. Korkisch and S. S. Ahluwalia, "Separation of Uränium by Combined Ion Exchange-Solvent Extraction," Anal. Chem. 38, 497-500 (1966).

42. Z. I. Dizdar and D. H. W. den Boer, "Purification of Plutonium by a Cation Exchanger," J. Inorg. Nucl. Chem. $\underline{3}^{\prime}$ 323-325 (1956).

43. M. N. Sastri and A. F, Rao, "Chromatographic Separations of Some Elements on Papers Impregnated with a Liquid Cation Exchanger," 2. Anal. Chem. 196, 166-169 (1963).

44. Z. Sulcek and V. Sixta, "Chromatographic Separation of Uranium from Excess of Thorium on silica Gel Column," Collec. Czech. Chem. Commun. 40, 2303-2308 (1975).

45. F. Tera and J. Korkisch, "Separation of Uranium by Anion Exchange," Anal. Chim. Acta 25, 222-225 (1961).

46. F. Tera, J. Korkisch, and F. Hecht, "Ion Exchange in Mixed So:vents.--IV. The Distribution of Thorium Between 
Alcohol-Nitric Acid Solutions and tne Strongly-Basic Anion Exchanger Dowex-l. Separation of Thorium From Uranium, : J. Inorg. Nucl. Chem. 16, 345-349 (1961).

47. K. A. Kraus, G. E. Moore, and F. Nelson, "Anion Exchange Studies. XXI. Th(IV) ard U(IV) in Hydrochloric Acid. Separation of Thorium, Protactinium and Uranium," J.Am. Chem. Soc. 78, 2692-2695 (1956).

48. D. G. Boase and J. K. Foreman, "The Separation of Sub-Microgram Amounts of Uranium from Milligram Amounts of Iron, Aluminium, and Plutonium," Talanta 으, 187-190 (1961).

49. J. K. Brody, J. P. Faris, and R. F. Buchanan, "Ion Exchange Spectrographic Method for Determination of Impurities in Uranium and Plutonium $p$ "Anal. Chem. 30, 1969-1912 (1958).

50. J. Korkisch and F. Tera, "Anion Exchange Separation of Uranium, Thorium, and Bismuth," Z. Anal. Chem. 186, 290-295 (1962).

5i. S. Urubay, J. Korkisch, and G. E. Janauer, "Anion Exchange of Uranium, Thorium, Iron, and Aluminium in Mineral Acid-Ether Solutions. Separation of Uranium from Thorium, Aluminium, and Iron," Talanta 10, 673-678 (1963).

52. J. Korkisch and G. Arrhenius, "Separation of Uranium, Thorium, and the Rare Earth Elements by Anion Exchange," Anal. Chem. 36, 850-854 (1964).

53. S. Ahrland, I. Grenthe, and B. Noren, "The Ion Exchange Properties of Silica Gel. I. The Sorption of $\mathrm{Na}^{+}$, $\mathrm{Ca}^{27}, \mathrm{Ba}^{2+}, \mathrm{UO}^{2}, \mathrm{Gd}{ }^{+}, \mathrm{Zr}(\mathrm{IV})+\mathrm{Nb}, \mathrm{U}(\mathrm{IV}), \quad$ and Pu(IV)," Acta Chem. Scand. 14, 1059-1076 (1960).

54. F. W. Tober, "Concentration and Purification of Uranium, Plutonium, and Neptunium by Ion Exchange in Nuclearly Safe Equipment," Proc. United Nations Int. Conf. Peaceful Uses of At. Energy, 2nd, Geneva, 1958 (United Nations, New York 1958), Vol. 17, pp. 574-584.

55. V. D. Zagrai and L. I. Sel'chenkov, "Chromatographic Separation of Microgram Amounts of Neptunium and Plutonium $\mathrm{Cn}$ the Cationites $\mathrm{KU}-1$ and KU-2," Radiokhimiya (English Translation) 4 , 161-164 (1962).

56. K. Watanabe, "Radiochemical Determination of Plutonium in the JRR-1 Irradiated Uranium," J. Atomic Energy Soc. Japan 3, 497-501 (1961) (in German).

57. F. P. Roberts and F. P. Brauer, "Sequential Separation of Some Actinide Elements by Anion Exchange," Hanford Atomic Products Operation report HW-60552 (June 1959). 
58. I. K. Kressin and G. R. Waterbury, "The Quantitative Separation of Plutonium from Various Ions by Anion Exchange," Arial. Chem. 34, 1598-1601 (1962).

59. R. A. Schneider and K. A. Harmon, "Analytical Solvent Extraction," in Analytical Technical Manual, Hanford Works report HW-53368 (February 1961).

60. R. P. Larse. and C. A. Seils, Jr., "Determination of Uranium and Plutonium in Uranium-Plutonium-Fission Element Alloys," Anal. Chem. 32, 1863-1866 (1960).

61. A. R. Eberle and M. W. Lerner, "Separation of Uranium from Thorium, Bismuth, and Ores with Tributyl Phosphate," Anal. Chem. 29, 1134-1139 (1957).

62. H. Levine and F. S. Grimaldi, "Determination of Thorium in the Parts Fer Million Range in Rocks," Geochim. Cosmocrim. Acta 14, 93-97 (1958).

63. J. C. Guyon and B. Madison, "Studies on the Solvent Extraction of Thorium," Mikrochim. Acta, 133-144 (1975).

64. D. Dyrssen, "Studies on the Extraction of Metal Complexes. XXXII. N-Phenylbenzohydroxamine-Acid," Acta Chem. Scand. 10, 353-359 (1956).

65. D. Dyrssen and V. Dahlberg, "Studies on the Extraction of Metal Complexes. VIII. The Extraction of La, Sm, Hf, Th, and U(VI) with Oxine and Cupferron," Acta Chem. Scand. I, 1186-1196 (1953).

66. R. Ko and M. R. Weiler, "Jpectrographic Determination of Thorium in Urárium Ore," Anal. Chem. 34, 85-87 (1962).

67. R. Shabana and H. Ruf, "Extraction and Separation of Neptunium, Uranium, Thorium, and Cerium with TOPO from Mixed Solvents," Radiochim. Acta 23, 117-120 (1976).

68. B. E. Paige, P. Goris, and J. E. Rein, "Determination of Uranium in Irradiated Thorium," Phillips Petroleum Co. report IDO-14411 (June 1957).

69. J. M. Crawford, Ed., "Analytical Chemistry Branch Annual Report for FY-1976 and Transition Quarter," Allied Chemical Corporation report ICP-1103 (December 1976): pp. 119-120.

70. C. L. Rulfs, A. K. De, and P. J. Elving, "Isolation and Measurement of Uranium at the Microgram Level," Anal. Chem. 28, $1139-11.43$ (1956).

71. C. A. Horton and J. C. White, "Separation of Uranium by Solvent Extraction with Tri-n-octylphosphine Oxide, Direct 
Colorimetric Determination with Dibenzoylmethane," Anal. Chem. 30, 1779-1784 (1958).

72. R. F. Clayton, W. H. Hardwick, M. Moreton-Smith, and R. Todd, "The Detarmination of Uranium by Solvent Extraction. II. The Separation of Uranium-233 from Irradiated Thorium as the Oxine Complex in the Presence of Ethylenediaminetetra-acetic Acid," Analyst 83, 13-23 (1958).

73. J. S. Fritz and M. Johnson-Richard, "Colorimetric Uranium Determination with Arsenazo," Anal. Chim. Acta 20, 164-171 (1959).

74. L. L. Galkina, "Separation of Rare-Earth Elements from Thorium, Scandium, and Uranium by Extraction with n-Butyric Acid," Radiokhimiya (English Translation) 8, 329-331 (1966).

75. W. D. Shuits and L. B. Dunlap, "Determination of Uranium (VI) by Tri-n-octylphosphine Oxide Extraction and Coulometric Titration," Anal. Chim. Acta 29, 254-260 (1963).

76. D. F. Peppard, G. W. Mason, and M. V. Gergel, "The Mutual Separation ji Thorium, Protactinium, and Uranium by Tributyl Phosphate Extraction from Hydrochloric Acid," J.

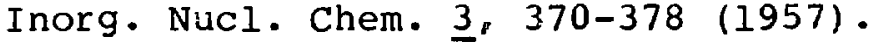

77. W. J. Maeck, G. L. Booman, M. C. Elliott, and J. E. Rein, "Spectrophotometric Extraction Methods Specific for Uranium,". Anal. Chem. 31, 1130-1134 (1959).

78. R. C. Shank, Ed., "Analytical Chemistry Branch Annual Report Fiscal Year 1975," Allied Chemical Corp. report ICP-1079 (October 1975 ), p. 54.

79. R. J. Baltisberger, "Separation and Determination of Trace Quantities of Uranium in Presence of Plutonium," Anal. Chem. 36, 2369-2370 (1964).

80. F. L. Moore and J. E. Hudgens, Jr., "Separation and Determination of Plutonium by Liquid-Liquid Extraction," Anal. Chem. 29, 1767-1770 (1957).

81. W. J. Maeck, G. L. Eooman, M. E. Kussey, and J. E. Rein, "Separation and Determination of Plutonium in Uranium-Fission Product Mixtures," Anal. Chem. 32, 1874-1876 (1960).

82. W. J. Maeck, M. E. Kussey, G. I. Booman, and J. E. Rein, "Spectrophotometric Extraction Method Specific for Plutonium," Anal. Chem. 33, 998-1001 (1961).

83. M. K. Chmutova and $Y$. A. Zolotov, "Investigation of the Extraction and Complex Formation of Plutonium (IV) with 
N-Benzoylphenylhydroxylamine,"

Translation) $\underline{6}, 625-630$ (1964).

84. B. Martin, D. W. Ockenden, and J. K. Foreman, "The Solvent

Extraction of Plutonium and Americium by Tri-n-octylphosphine oxide," J. Inorg. Nucl. Chem. 2l, 96-107 (1961).

85. A. W. Mosen, General Atomic Co., personal communication, December 1977.

86. E. M. Knox, "Determination of Thorium in Solvent Extraction Organic Phase without Stripping," in Analytical Chemistry Department Annual Report, 1975, A. W. Mosen, Ed., General Atomic Company report GA-A14104 (October 1976), p. 29.

87. C. J. Rodden, Ed., Selected Measurement Methods for Plutonium and uranium in the Nuclear Fuel cycle (Office of Information Services, US Atomic Energy commission, Virginia, 197\%), pp. 70-74.

88. C. Duval, Inorganic Thermogravimetric Analysis, 2nd Ed. (Elsevier Publishing Co., Amsterdam, 1963).

89. J. M. Crawford, Ed., "Analytical Methods Manual, Part I. Methods Used by the Remote and Service Analysis Laboratory," Allied Chemical Corp. report ICP-1029 (October 1973), pp. U-Grav-1, 1-2.

90. M. H. Fletcher, F. S. Grimaldi, and L. B. Jenkins, "Thoron-meso-Tartaric Acid System for Determination of Thorium," Anal. Chem. 29, 963-967 (1957).

91. D. V. Matutina, F. C. Rowlin, and R. G. Wilbourn, "Spectrophotometric Determination of Thorium with Thorin," in Analytical Chemistry Department Annual Report, 1974, General Atomic Co. report GA-A13536 (October 1975), pp. $20-21$.

92. J. Korkisch and G. E. Janauer, "Spectrophotometric Determination of Thorium with Solochromate Fast Red," Anal. Chem. 33, 1930-1933 (1961).

93. G. Banerjee, "Direct Spectrophotometric Determination of Thorium with SPADNS," Anal. Chim. Acta 16, 56-61 (1957).

94. S. B. Savvin, "Analytical Use of Arsenazo III. Determination of Thorium, Zirconium, Uranium, and Rare Earth Elements," Talanta 8, 673-685 (1961).

95. C. A. Prohaska, "A Flow Colorimeter for Measuring Uranium Concentration in Process Streams," E. I. Dupont de Nemours and Co. report DP-229 (August 1957). 
96. F. A. Scott and R. D. Dierks, "Photometer for Continuous Determination of Uranium in Radioactive Process Streams," Anal. Chem. 32, 268-272 (1960).

97. American Society for Testing Materials, 1974 Annual Book of ASTM Standards, Part 45, Nuclear Standards (ASTM, Philadelphia, 1974), pp. 709-714.

98. K. L. Cherg and P. F. Lott, "Reaction of Hydrogen Peroxide with Complexes of (Ethylenedinitrilo)-Tetraacetic Acid and Nitrilotriacetic Acid," Anal. Chem. 28, 462-465 (1956).

99. W. I. Winters, "Spectrophotometric Determination of Uranium in Nuclear Waste," Atlantic Richfield Hanford Co. report ARH-SA-250 (1976).

100. W. I. Winters, "Spectrophotometric Determination of Trace Uranium in Plutonium Nitrate and oxide with 2-12Pyridylazo)-5-Diethylaminophenol," Atlantic Richfield Hanford Co. report ARH-ST-116 (1975) .

101. L. Sommer, V. M. Ivanov, and H. Novotna, "The Reaction of Uranyl Ions with 4-(2-Pyridylazo) Resorcinol," Talanta 1.4, 329-343 (1967).

102. S. Shibata, M. Furukawa, and Y. Ishiguro, "Spectrophotometric Determination of Uranium with 1-[15-Methyl-2(Pyridyl)azo]-2-Napthol," Mikrochim. Acta, 1974, 123-133.

103. D. A. Johnson and T. M. Florence, "Spectrophotometric Determination of Uranium (VI) with 2-(5-Bromo-2pyridylazo)-5-dietnylaminophenol," Anal. Chim. Acta 53, $73-79$ (1971).

104. D. D. Jackson, R. M. Hollen, S. F. Marsh, M. R. Ortiz, and J. E. Rein, "Determination of Submilligram Amounts of Uranium with the LASL Automated Spectrophotometer," in Analytical Chemistry in Nuclear Fuel Reprocessing, W. S. Lyon, Ed. (Science Press, Princeton, 1978), pp. 126-133.

105. D. D. Jackson, D. J. Hodgkins, R. M. Hollen, and J. E. Rein, "Automated Spectrophotometer for Plutonium anả Uranium Determination," Los Alamos Scientific Laboratory report LA-6091 (February 1976).

106. A. L. Henicksman, Los Alamos Scientific Laboratory, personal communication, January 197.8 .

107. S. D. Reeder, "Determination of Uranium in HTGR Samples Containing Thorium," in Analytical Chemistry Branch Arnual Report Fiscal Year 1974, R. C. Shank, Ed., Allied Chemical Corp. report ICP-1056 (October 1974), p. 82 . 
108. G. Phillips, "Precise Determination of Plutonium by Differential Spectrophotometry," Analyst 83, 75-79 (1958).

109. W. I. Winters, "The Differential Spectrophotometric Determination of Plutonium Using the Cary Model 16 Spectrophotomeier," Atlantic Richfield Hanford Co. report ARH2745 (1973).

110. J. W. Dahlby and G. R. Waterbury, "The Spectrophotometric Determination of Plutonium as the Arsenazo I Complex," Los Alamos Scientific Laboratory report LA-3314 (July 1965).

111. C. N. Reilley and R. W. Murray, "Introduction to Electrochemical Techniques," in Treatise on Analytical Chemistry, I. M. Kolthoff and P. J. Elving, Eds. (John Wiley and Sons, Inc., New York, 1963), Part I, Vol. 4, Chap. 43, pp. 2187-2189.

112. W. D. Shults, "Applications of Controlled-Potential Coulometry to the Determination of Plutonium," Talanta 10 , 833-849 (1963).

113. G. C. Goode and J. Herrington, "High-Speed ControlledPotential Coulometry, Application to Precise Determination of Flutonium," Anal. Chim. Acta 33, 413-417 (1965).

Il4. G. Goldstein, D. L. Manning, and H. E. Zittel, "Iron (II) as an Indicator Ion for Amperomecric Titrations with (Ethylenedinitrilo) tetraacetic Acid, Application to the Determination of Thorium," Anal. Chem. 34, 358-361 (1962).

115. C. L. Sharma and P. K. Jain, "Diphenic Acid as a Selective Reagent for the Amperometric Determination of Thorium(IV)," Talanta 24, 754-755 (1977).

116. W. Davies and W. Gray, "A Rapid and Specific Titrimetric Method for the Precise Determination of Uranium Using Iron (II) Sulphate as Reductant," Talanta 11, 1203-1211 (1964).

117. A. R. Eberle, M. W. Lerner, C. G. Goldbeck, and C. J. Rodden, "Titrimetric Determination of Uranium in Product, Fuel, and Scrap Materials After Ferrous Ion Reduction in Phosphoric Acid," New Brunswick Laboratory report NBL-252 (July 1970).

118. G. C. Goode, J. Herrington, and G. Hall, "The Determination of Uranium in the Presence of Plutonium by Controlled Fotential Coulometry, Application to the Analysis of Fuel Element Processing Solutions," Anal. Chim. Acta 30, 109113 (1964). 
119. J. T. Byrne, M. K. Larsen, and J. L. Pflug, "Accurate Determination of Uranium in the Presence of Small Amounts of Molybdenum," Anal. Chem. 31, 942-945 (1959).

120. J. E. Harrar, W. G. Boyle, J. D. Breshears, C. L. Pomernacki, H. R. Brand, A. M. Kray, R. J. Sherry, and J. A. Pastrone, "An Automated Sample-Processing and Titration System for the Determination of Uranium," Nucl. Mater. Manage. V(III), 199-210 (1976).

121. C. A. Seils, Jr., R. J. Meyer, and R. P. Larsen, "Amperometric Titration of Plutonium (VI) with Iron (II)," Anal. Chem. 35, 1673-1675 (1963).

122. K. S. Bergstresser and G. R. Waterbury, "An Evaluation of the Amperometric Titration of Plutonium," Los Flamos Scientific Laboratory report LA-3091 (1964).

123. J. L. Drummond and R. A. Grant, "Potentiometric Determination of Plutonium by Argentic oxidation, Ferrous Reduction, and Dichromate Titration," Talanta 13, 477-488 (1966).

124. G. R. Waterbury and C. F. Metz, "Precise Determination of Plutonium by Potentiometric Titration," Anal. Chem. 3l, $1144-1148$ (1959).

125. W. N. Carson, Jr., J. W. Vanderwater, and H. S. Gile, "Coulometric Determination of Plutonium," Anal. Chem. 29, 1417-1422 (1957).

126. C. E. Pietri and J. A. Baglio, "The Determination of Plutonium Based on National Bureau of Standards Potassium Dichromate," Talanta 6, 159-166 (1960).

127. R. J. Kofoed, Jr., "Plutonium Oxidation-Reduction Titrations," Hanford Atomic Products operation report HW-53368 Suppl. (December 1963).

128. G. Phillips and D. Crossley, "The Determination of Plutonium/Uranium Ratios by Controlled-Potential Coulometry at a Solid Electrode," Atomic Energy Research Establishment report AERE-R-8794 (May 1977).

129. "Analytical Methods for the Titrimetric Determination of Plutonium (Chromous Reduction-Ceric Sulphate Titration)," United Kingdom Atomic Energy Authority repor'c PG309(W) (1962).

130. D. D. Jackson, R. M. Hollen, F. R. Roensch, and J. E. Rein, "Highly Selective Coulometric Method and Equipment for the Automated Determination of Plutonium," in Analytical Chemistry in Nuclear Fuel Reprocessing, w. S. Lyon, Ed., (Science Press, Prínceton, 1978) pp. 151-158. 
131. G. S. Barney, "Coulometric Determination of Plutonium in Solutions of Dissolved Reactor Fuel Elements," Atlantic Richfield Hanford Co. report ARH-SA-55 (January 1970).

132. F. A. Scott and R. M. Peekema, "Analysis for Plutonium by Controlled-Potential Coulometry," Proc. United Nations Int. Conf. Peaceful Uses of At. Energy, 2nd, Geneva, 1958 (United Nations, New York, 1958), Vol. 28, pp. 573-578.

133. C. R. McGowan and J. K. Foreman, "In-Line Analytical Instrumentation of Nuclear Fuel Reprocessing Plants," in Progress in Nuclear Energy, Series IX, Analytical Chemistry, Vol. 7, H. A. Elion and D. C. Stewart, Eds. (Pergamon Press, Oxford, 1966), pp. 111-176.

134. C. E. Michelson and K. Koyama, "Process Polarography: Some Problems in the Automatic Determination of Uranium in Nitric Acid," Hanford Atomic Products operation report HW-42637 (April 1956).

135. F. Elliott and J. K. Foreman, "Some Observations on the Application of Polarography to Industrial Atomic Energy Analysis," in Advances in Polarography, Proceedings of the 2nd International Congress Held at Cambridge (England): 1959, I. S. Longmuir, Ed. (Pergamon Press, New York, 1960); pp. $538-550$.

136. G. J. Alkire, K. Koyama, K. J. Hahn, and C. E. Michelson, "Plant-Type Polarographic System for Determining Uranium in Radioactive waste Streams," Anal. Chem. 30, 1912-1S15 (1958).

137. R. P. Graham and G. B. Larrabee, "Polarographic Determinations of Thorium," Analyst 82, 415-422 (1957).

138. P. Mechelynck, "The Use of Electrochemical Methods for Remote-Control Analysis of Radioactive Substances at Various Stages of Reprocessing," Proc. United Nations Int. Conf. Peaceful Uses of At. Energy, 2nd, Geneva, 1958 (United Nations, New York, 1958), Vol. 28, pp. 579-582.

139. H. W. Bertram, M. W. Lerner, G. J. Petretic, E. S. Roszkowski, and C. J. Rodden, "Automatic Determination of Uranium in Process Streams," Anal. Chem. 30, 354-359 (1958).

140. K. Motojima, H. Okashita, and T. Sakamoto, "Polarographic Determination of Uranium in the waste Solution of Nuclear Fuel Reprocessing," Japan Analyst 13, 1097-1100 (1964).

141. K. Motojima and K. Katsuyama, "Polarographic Determination of Uranium in the Reprocessing of Nuclear Fuel," Japan Analyst 12, 358-363 (1963). 
142. J. A. Lewis and K. C. Overton, "Automatic Recording of Ion Concentration in Flowing Solution," Analyst $\underline{79}, 293.297$ (1954).

143. R. C. Propst, "In-Line Polarography of Uranium in Process Waste," E. I. duPont de Nemours and Co. report DP-572 (June 1961).

144. B. G. Brodda, P. Filss, H. Kirchner, and U. Wenzel, "Analysis and Material Balance in the Reprocessing of HTGR Fuels," Kernforschungsanlage Julich report JUL-1033-CT (December 1973).

145. K. Koyama, "Square-Wave Polarography of Plutonium," Anal. Chem. 3ㄴ, 523-524 (1960).

146. J. S. Fritz, R. T. Oliver, and D. J. Pietrzyk, "Chelometric Titrations Using an Azoarsonic Acid Indicator," Anal. Chem. 30, 111-114 (1958).

147. D. I. Ryabchikov and E. K. Gol'braikh, The Analytical Chemistry of Thorium (The MacMillan Co., New York, 1903).

148. J. J. Fritz and J. J. Ford, "Titrimetric Determination of Thorium," Anal. Chem. 25, 1640-1642 (1953).

149. B. H. J. de Heer, T. van der Plas, and M. E. A. Hermans, "The Successive Compleximetric Determination of Thorium and Uranium in Nitrate Solution," Anal. Chili. Acta 32, 292-2.93 (1965).

150. A. G. Rykov, E. M. Piskunov, and G. A. Timofeev, "Direct Complexometric Determination of Thorium(IV), Uranium(IV), Neptunium(IV), and Plutonium(IV) by Titration with Diethylenetriaminepentaacetic Acid in the Presence of Xylenol Orange as Indicator," Zh. Anal. Khim. (English Translation) 30, 598-601 (1975).

151. P. N. Palei and Z. K. Karalova, "Effect of Fluorides on the Determination of Uranium in the Presence of Beryllium," 2 h. Anal. Khim. (English Translation) 17, 525-526 (1962).

152. G. W. C. Milner and J. L. Woodhead, "The Volumetric Determination of Plutonium with Ethylenediaminetetra-acetic Acid," Analyst 81, 427-429 (1956).

153. F. N. Falei and Chang Wen-ts'ing, Determination of Quadrivalent Plutonium Indicator," $\mathrm{zh}$. Anal. Khim. (English 683-685 (1960).

"Complexonometric Using Arsenazo as Translation) 15 , 
154. W. B. Brown, D. R. Rogers, E. A. Iershad, and W. R. Amos, "The Determination of Plutonium by (Ethylene dinitrilc)-tetraacetic Acid Titration," Anal. Chem. 35, 1000-1002 (1963).

155. D. G. Boase, J. K. Foreman, and J. L. Drummond, "The Complexometric Determination of Plutonium in Reactor Fuel Processing Plant Solutions - I. Nitric Acid Solutions of Irradiated Uranium," Talanta $\underline{9}$, 53-63 (1962).

156. J. E. Rein and C. F. Metz, "Advantages and Limitations of Mass Spectrometry for the Measurement of the Isotopic Distributions of Uranium and Pluionium and Applications to Nuclear Fuel Burnup," in Analytizal Chemistry of Nuclear Fuels, Proc. of a Panel, Vienna, 1970 (International Atomic Energy Agency, Vienna, 1972), pp. 135-142.

157. E. L. Garner, L. A. Machlan, and W. R. Shields, "Standard Reference Materials: Uranium Standard Reference Materials," National Bureau of Standards Special Publ. 260-27 (April 1971).

158. A. von Baeckmann, J. Neuber, M. Wilhelmi, and L。 Koch, "Automatic Analysis of Uranium and Plutonium in Solutions," in Analytical Methods in the Nuclear Fuel Cycle, Proc. Symp., Vienna, 1971 (International Atomic Energy Agency, Vienna, 1972), paper IAEA-SM-149/42, pp. 329-341.

159. L. Koch, "Determination oi Isotopic Concentrations of Uranium and Plutonium," Radiocnim. Acta 12, 160-162 (1969) (in German; English abstract).

160. J. E. Rein and C. F. Metz, "The Application of Isotope Dilution Mass Spectrometry to the Determination of Uranium and Plutonium in Nuclear Fuels," in Analytical Chemistry of Nuclear Fuels, Proc. Panel, Vienna, 1970 (International Atomic Energy Agency, Vienna, 1972), pp. 97-109.

161. H. Bokelund, "Determination of Plutonium by Isotope Dilution Mass spectrometry Following TTA-Extraction," J. Radioanal. Chem. 2, 191-196 (1969).

162. R. E. Perrin, Los $f_{\text {anos }}$ Scientific Laboratory, personal communication, January 1977.

163. T. D. Reilly and M. L. Evans, "Measurement Reliability for Nuclear Material Assay," Los Alamos Scientific Laboratory report LA-6574 (January 1977).

164. R. E. Perrin, "Data Summary 1976 Meeting," Minutes $1976 \quad$ Plutonium Livermore, California, November 1976.

Plutonium Exchange
Exchange Meeting, 
105. J. A. Carter and R. L. Walker, "Preparation and Isotopic Analysis of $U$ and $P u$ for Safeguards," in Analytical Chemistry in Nuclear Fuel Reprocessing, W. $S$. Lyon, Ed., Proc. 2lst Conf. Analytical Chemistry in Energy Technology, GatIinburg, Tennessee, October 4-6, 1977 (Science Press, Princeton, 1978), pp. 84-92.

166. W. D. Unger, Ed., "Advanced Fuel Cycle Program Progress Report for Period July 1 to September 1, 1977," Oak Ridge National Laboratory report ORNL/TM-6092 (November 1977), pp. $2-27$ to $2-29$.

167. R. E. Perrin, Los Alamos Scientific Laboratory, personal Communication, April 1977.

168. A. von Baeckmann, "Destructive Analysis of Nuclear Materials for Safeguards," in Practical Applications of $R$ and $D$ in the ield of Safeguards, Proc. Symp., Rome, 7974 (European Safeguards Research and Development Association, Rome, 1974), p. 368 .

169. R. A. Schneider and K. M. Harmon, "Analytical Technical Manual," Hanford Atomic Products Operation report HW -53368 (February 1961).

170. L. Cathey and W. J. Jenkins, "The Operation of Solid-State Alpha Counters in Chemical Process Streams," IRE Trans. Nucl. Sci. NS-9, 193-199 (June 1962).

171. U. L. Upson, "Scintillating Glasses for Alpha Counting," Hanford Atomic Products Operation report HW-72512 (January 1962).

172. C. E. Huck and J. D. Lodge, "In-Line Plutonium Analysis by Use of Alpha Scintillating Glass and X-Ray Scintillation Techniques," Hanford Atomic Products Operation report HW-84251 (October 1964).

173. O. H. Koski, "The Optimization of Cerium-Activated Glass Alpha Sensors," Battelle Pacific Northwest Laboratories r.port BNWL-CC-2354 (December 1969).

174. H. W. Randolph, "Monitor Cell for Alpha Activity in Liquid Process Streams," Nucl. Instr. Meth. 74, 351-352 (1969).

175. T. Gozani and $K$. Crosbie, "The Optimization of On-Line Alpha Monitors," Trans. ANS 17, 322-323 (1973).

176. T. Gozani, "Pulse Shape Differences in Thin Glass Scintillators," Trans. ANS 28, 67-68 (1974). 
177. K. J. Hofstetter, G. M. Tucker, R. P. Kemmerlin, J. H. Gray, and G. A. Huff, "Application of On-Line Alpha Monitors to process Streams in a Nuclear Fuel Reprocessing Plant," in Nuclear Safeguards Analysis, Nondestructive and Analytical Chemical Techniques in Nuclear Safeguards, E. A. Hakkila, Ea., (American Chemical Society, Washington, DC, in press).

178. G. A. Huff, Allied-General Nuclear Services, personal communication, March 1978.

179. S. F. Kozlov, E. A. Konorova, M. I. Krapivin, V. A. Nadein, and V. G. Yuãina, "Usage of Diamond Detectors as Immersed Alpha-Counters," IEEE Trans. Nucl. Sci. NS-24, 242-24j (1977).

280. M. H. Campbell, "Fluorimetric Uranium Analysis with a High Carbonate Flux," Hanford Atomic Products Operation report HW-53455 (November 1957).

181. F. A. Centanni, A. M. Ross, and M. A. Desesa, "Fluorometric Determination of Uranium," Anal. Chem. 28, 1651-1657 (1956).

182. R. A. Schneider and K. M. Harmon, "Fluorimetríc Determination of Uranium," in Analytical Technical Manual, Hanford Atomic Products Operation report HW-53368 (February 1961) PP. U-Fluor-1 to U-Fluor-2.L.

183. M. W. Lerner, "Evaluation of the Methods in TID-7029, Selected Measurement Methods for Plutonium and Uranium in the Nuclear Fuel Cycle," New Brunswick Laboratory report NBL-231 (February 1966).

184. B. Fleet and A. Y. W. Ho, "Applications of Ion-Selective Electrodes in Continuous Analysis," in Ion Selective Electrodes, Symposium held at Matrafured, Hungary, October 23-25, 1Y72, E. Pungor, Ed., (Akademiai Krado, Budapest, 1973), pp. 17-35.

185. N. Lakashminarayaniăh, Membrane Electrodes (Academic Press, New York, 1976).

186. P. L. Bailey, Analysis with Ion-Selective Electrodes, (Heyden, London, 1977).

187. G. J. Moody and J. D. R. Thomas, "Development and Publication of Work with Selective Ion-Sensitive Electrodes," Talanta 19, 623-639 (1972).

188. R. P. Buck, "Ion Selective Electrodes," Anal. Chem. $\underline{48}$, $23 R-39 R$ (1976). 
189. J. B. Harrell, A. D. Jones, and G. R. Chapin, "A Liquid Ion-Exchange Nombrane Electrode for Polyvalent Cations," Anal. Chem. 4l, 1459-1462 (1969).

190. W. C. Dietrich and D. L. Manning, "Uranium Sensitive Electrode Membrane," U. S. Patent No. 3864 233, February 1975 .

191. D. L. Manning, J. R. Stokely, and D. W. Mayouyrk, "Studies on Several Uranyl Organophosphorus Compounds in a Poly (Vinyl Chloride) (PVC) Matrix as Ion Sensors for Uranium," Anal. Chem. 46, 1116-1119 (1974).

192. W. D. Spall, M. R. Ortiz, and S. F. Marsh, "Specific Ion Electrodes as Detectors," in Examination of Fast Reactor Fuels, FBR Analytical Quality Assurance Standards and Methods and Analytical Methods Development-Irradiation Tests, July 1-September 30, 1977, R. D. Baker, Comp., Los Alamos Scientific Laboratory report LA-7038-PR (November 1977), p. 15 .

193. E. P. Bertin, "Recent Advances in Quantitative X-Ray Spectrometric Analysis by Solution Techniques," Adv. X-Ray Anal. 11, 1-22 (1968).

194. E. P. Bertin, Principles and Practice of $x$-Ray Spectrometric Analysis (Plenum Press, New York, 1970).

195. L. S. Birks and J. V. Gilfrich, "X-Ray Spectrometry," Anal. Chem. 48, 273R-281R (1976).

196. R. Woldseth, All You Ever Wanted to Know About X-Ray Energy Spectrometry (Kevex Corp., Burlingame, California, 1973).

197. J. Kierzek and J. L. Parus, "Rapid Method of Uranium Determination in Solutions Based on $\mathrm{X}$-Ray Fluorescence and Absorption," J. Radioanal. Chem. 24, 73-84 (1975).

198. J. F. Klecka, "Quantitative Analysis of Uranium and Thorium Solutions with a Semiconductor $X$-Ray Emission Spectrometer," University of California Radiation Laboratory report UCRL-17166 (1966).

199. N. Bachvarov, T. Dragnev, S. Georgiev, J. Karamanova, T. Ruskov, and T. Tomov, "Quantitative Determination of $U$ Content anỏ Its U-235 Enrichment by Combined Gamma X-Ray Fluorescent Measurements," Radiochem. Radioanal. Lett. 14, $1-8 \quad(1973)$.

200. A. G. Miller, "Analytical Utility of the M Series X-Ray Emission Lines Applied to Uranium, Neptunium, Plutonium, and Americium," Anal. Chem. 48, 176-178 (1976). 
201. O. Menis, E. K. Halteman, and E. E. Garcia, "X-Ray Emission Analysis of Plutonium and Uranium Compound Mixtures," Anal. Chem. 35, 1049-1052 (1963).

202. G. Pish and A. A. Huffman, "Quantitative Determination of Thorium and Uranium in Solutions by Fluorescent X-Ray Spectrometry," Anal. Chem. 27, 1875-1878 (1955).

203. B. G. Brodaa, H. Lammertz, H. Maselter, and J. Vieth, "Remotely Controlled Computer-Guided Preparation Facility for X-Ray Fluorescence Measurement Samples at a Fuel Reprocessing Plant," Kerntechnik 19, 433-444 (1977).

204. A. von Baeckmann, D. Ertel, and J. Neuber, "Determination of Actinide Elements in Nuclear Fuels by X-Fay Analysis," Adv. X-Ray Anal. 18, 62-75 (1975).

205. D. Ertel, "Simultaneous Determination of Uranium and Plutonium in Inactive Purex Process Solutions by $x-R a y$ Fluorescence," J. Radicanal. Chem. 2, 205-209 (1969).

206. G. Malet and G. Charpentier, "Simultaneous Determination of Uranium and Plutonium by X-Ray Fluorescence in the Reprocessing of Rhapsodie Fuel," in Analytical Methods in the Nuclear Fuel Cycle, Proc. Symp., Vienna, November 29December 3, 1971 (International Atomic Energy Agency, Vienna, 1972), pp. 343-352.

207. M. Ganivet and T. Arnal, "Dosage du Plutonium dans les Alliages Plutonium-Aluminium par Fluorescence-X," Anal. Chim. Acta 39, 73-79 (1967) (in French).

208. C. Shenberg and S. Amiel, "Analytical Significance of Peaks and Peak Ratios in X-Ray Fluorescence Analysis Using a High Resolution Semiconductor Detector," Anal. Chem. 43 , $1025-1030$ (1971).

209. J. C. McCue, L. L. Bird, C. A. Ziegler, and J. J. O'Connor, "x-Ray Rayleigh Scattering Method for Determination of Uranium in Solution," Enal. Chem. 33, 41-43 (1961).

210. L. S. Birks and E. J. Brooks, "Analysis of Uranium Solutions by X-Ray Fluorescence," Anal. Chem. 23, 707-709 (1951).

211. P. A. Pella and A. von Baeckmann, "The X-Ray Spectrometric Determination of Uranium ana Plitonium in Solutions of Spent Nuclear Fuels," Anal. Chim. Acia. 47, 431-438 (1969).

212. W. L. Pickles and J. L. Cate, Jr., "Quantitative Nondispersive X-Ray Fluorescence Analysis of Highly Radioactive Samples for Uranium and Plutonium Concentration," University of California Radiation Laboratory report UCRL-74717 (August 1973). 
213. A. Gibbs, "Evaluation of a Gamma/X-Ray Spectrometer System for the Nondestructive Analysis of Plutonium and Uranium," E. I. duPont de Nemours and Co. report DPSU-74-11-20 (November 1974).

214. D. Ertel and $w$. Wettstein, "Bestimmung von Thorium und Uranium durch Roentgenfluoreszenzanalyse," Kernforschungszentrum Karlsruhe report KFK-560 (March 1967) (in German).

215. E. A. Hakkila, "A Critical Review of Conventional Analytical Techniques for Fissile Materials," in Coordinated Safeguards for Materials Management in a Fuel Reprocessing plant, Vol. II, Los Alamos scientific Laboratory report LÄ-6881 (September 1977), Appendix F.

216. E. A. Hakkila, "Analytical Chemistry and Nuclear Safeguards in a liuclear Fuel Reprocessing Plant," Nucl. Mater. Manage. VI(III), 466-471 (197\%).

217. E. A. Hakkila, "Analytical Chemistry Needs for Nuclear Safeguards in Nuclear Fuel Reprocessing," in Analytical Chemistry in Nuclear Fuel Reprocessing, w. S. Lyon, Ed. (Science Press, Princeton, 1978), pp. 24-31.

213. G. Phillips and G. W. C. Milner, "Controlled-Potential Coulometers Based Upon Modular Electronic Units. Part I Development of Equipment," Analyst 94, 833-839 (1969). 